\title{
Recent progress and future prospects of sodium-ion capacitors
}

\author{
Rui Jia ${ }^{1}$, Guozhen Shen ${ }^{2 *}$ and Di Chen ${ }^{1 *}$
}

\begin{abstract}
To satisfy the requirements for various electric systems and energy storage devices with both high energy density and power density as well as long lifespan, sodium-ion capacitors (SICs) consisting of battery anode and supercapacitor cathode, have attracted much attention due to the abundant resources and low cost of sodium source. SICs bridge the gap between the batteries and the supercapacitors, which can be used as competitive candidates for large-scale energy storage. In this review, the battery-type anode materials and the capacitor-type cathode materials are classified and introduced in detail. The advantages of various electrolytes including organic electrolytes, aqueous electrolytes and ion liquid electrolytes are also discussed sequentially. In addition, from the perspective of practical value, the presentations of the SICs at the current situation and the potential application in urban rail are displayed. Finally, the challenge, future research and prospects towards the SICs are put forward.
\end{abstract}

Keywords: sodium-ion, hybrid capacitors, battery-type anode, capacitor-type cathode, electrolytes

\section{INTRODUCTION}

With the increasing consumption of traditional fossil fuels and growing serious environment pollution, the development of clean energy (such as wind energy and solar power) and efficient energy storage systems (ESS) has become more and more important [1-9]. Commercial lithium ion batteries (LIBs) possessing high energy density $\left(150-200 \mathrm{~W} \mathrm{~h} \mathrm{~kg}^{-1}\right)$ are restricted by low power density (less than $350 \mathrm{~W} \mathrm{~kg}^{-1}$ ). Meanwhile, supercapacitors (SCs) owning high power density $\left(\sim 10 \mathrm{~kW} \mathrm{~kg} \mathrm{~kg}^{-1}\right)$ are limited by low energy density (no more than $10 \mathrm{~W} \mathrm{~h} \mathrm{~kg}^{-1}$ ) [10,11]. In the past decades, many efforts have been made to boost the power and energy densities of the batteries and capacitors, respec- tively. For instance, with the advent of electric vehicles (EVs), which require long lifespan (> 10 years) and a high power density (>1000 $\mathrm{W} \mathrm{kg}^{-1}$ ), lithium-ion hybrid capacitors (LICs) combining the features of high energy and high power densities were developed [12-19]. Compared with SCs and LIBs, LICs combine the advantages of the above two types of energy storage devices. However, the element of lithium on earth is not rich and geographically limited in the worldwide, resulting in the price of lithium skyrocketing with the appearance of EVs. The high cost restricts the large-scale application of LICs in ESS. On the other hand, sodium $(\mathrm{Na})$ has similar chemical properties to $\mathrm{Li}$ and abundant resource $(2.75 \%$ of $\mathrm{Na}$ to $0.065 \%$ of $\mathrm{Li}$ on earth) [20]. Additionally, sodium does not react with aluminum, which makes it possible to replace the expensive copper current collector. Consequently, sodium ion capacitors (SICs) have attracted much attention since 2012 [21-25].

The charge storage mechanism of hybrid capacitor is based on reversible anion adsorption/desorption on the surface of the cathode and $\mathrm{Na}$-ion reversible intercalation/de-intercalation in the anode [5,7]. The SICs generally exhibit higher energy densities from the Faradic reactions of battery-type anode than SCs and higher power densities from the capacitive reaction on the cathode than the batteries. Although SICs can bridge the gap between SCs and batteries, the energy and power densities of SICs are still dissatisfying by the requirements of large-scale ESS at present. The reason is that the radius of Na-ion $(1.02 \AA)$ is larger than that of Li-ion $(0.76 \AA)$, which results in sluggish $\mathrm{Na}$-ion diffusion and subversive structure changes in electrode materials during the charge and discharge process and reduces the rate capacity and cycling properties [26]. That is to say, SICs devices are in the primary stage of development and still face myriad problems from the electrode materials, electrolytes and

\footnotetext{
${ }^{1}$ School of Mathematics and Physics, University of Science and Technology Beijing, Beijing 100083, China

${ }^{2}$ State Key Laboratory for Superlattices and Microstructures, Institute of Semiconductors, Chinese Academy of Sciences, Beijing 100083, China

* Corresponding authors (emails: chendi@ustb.edu.cn (Chen D); gzshen@semi.ac.cn (Shen G))
} 
practical applications. Nonetheless, the late beginning also means more opportunities and progress should be achieved via solving the complicated questions.

In this review, we summarize the recent progress of SIC devices, which is disserted as following: (1) electrode materials including anode materials (carbon materials, transition metal oxides and compounds, transition metal chalcogenides and nitrides, MXenes, sodium super ion conductor (NASICON) materials and alloys) and cathode materials (porous carbon materials, MXenes and Prussian blue (PB) materials), (2) electrolyte (aqueous, organic and ionic liquid electrolytes), (3) presentation and potential application of the SICs. At the end of the review, we discuss the emerging questions in SICs and put forward our suggestions in responds to the existing problems for the future perspectives.

\section{STRATEGIES TOWARD ELECTRODE MATERIALS OF SICs}

The electrode materials play a very important role in the electrochemical properties of SICs. The anode materials of SICs as Na-ion hosts should have expanded lattice spacing, improved surface-controlled pseudocapacitance and reduced diffusion distance to enhance the kinetic behaviors. For example, the carbon materials with heteroatom doping, transition metal oxides and compounds, transition metal chalcogenides and nitrides, MXenes, NASICON and alloys are often involved. As for the cathodes, the materials with the features of high specific surface area and good electrical conductivity are necessary, such as porous carbon, MXenes and PB. In the following part, the developments on the anode and cathode materials during the past several years are described in details.

\section{Battery-type anode materials}

\section{Carbon materials}

Carbon materials are regarded as promising candidates for $\mathrm{Na}$-ion storage, due to their abundance in reserve, excellent electrical conductivity, high chemical stability and adjustable structure [27-34]. Most studies have focused on disordered carbon with large interlayer distance and numerous voids, which are beneficial to Na-ion insertion/extraction. In addition, some reports also involved the ordered carbon with uniform pore structures, which can contribute to facilitating the ion diffusion. In the early stage of SICs research, the sodium pre-doped hard carbon//activated carbon (AC) device fabricated by Kuratani and co-workers [35] in 2012 was the first report confirming that the sodium pre-doped hard carbon can stand a high current density applicable to capacitors. However, the SICs with the reported hard carbon as anode materials possess a low capacity and voltage, which needs to be further enhanced [36-38]. Graphite as the typical anode material in Li-based ESS is not suitable for Na-ion intercalation because of unfavorable mismatch between the size of Na-ion and the well-ordered structure [39]. Fortunately, in 2015, Han et al. [40] introduced $\mathrm{Na}^{+}-$ diglyme co-intercalation method, realizing the reversible Na-ion insertion into graphite. The decent energy and power densities of $93.5 \mathrm{~W} \mathrm{~h} \mathrm{~kg}^{-1}$ and $2823 \mathrm{~W} \mathrm{~kg}^{-1}$ in the potential window of 1-4 $\mathrm{V}$ were obtained from the graphitic mesocarbon microbead (MCMB)//AC device. Even after 3000 cycles, the capacitance retention still remains $98.3 \%$, suggesting a good cycling performance of $\mathrm{MCMB} / / \mathrm{AC}$ based SICs. Moreover, the reduced graphene oxide ( $\mathrm{rGO}$ ) has also been used as anode, in which the $\mathrm{Na}^{+}$can intercalate by reduction of $\mathrm{C}=\mathrm{O}$ groups to $-\mathrm{O}-$ $\mathrm{Na}$ or be stored by noncovalent interaction between the rGO layers. The $\mathrm{rGO} / / \mathrm{Na}_{0.21} \mathrm{MnO}_{2}$ based SIC [41] in $\mathrm{Na}_{2} \mathrm{SO}_{4}$ aqueous electrolyte with the voltage of $2.7 \mathrm{~V}$ shows high energy density of $31.8 \mathrm{~W} \mathrm{~h} \mathrm{~kg}^{-1}$ and high power density of $8000 \mathrm{~W} \mathrm{~kg}^{-1}$. After 1000 cycles, the capacitance remained $86.7 \%$ of the initial value without water splitting.

Designing porous carbon materials with two dimensional $(2 \mathrm{D}) / 3 \mathrm{D}$ structure and introducing heteroatom $(\mathrm{N}$, $\mathrm{O}, \mathrm{S}, \mathrm{P}$ ) into the carbon network can improve the energy storage performance [29]. In general, the $2 \mathrm{D}$ or $3 \mathrm{D}$ porous structure can enhance the rapid transportation, migration and diffusion of sodium ions and supply abundant active sites for reactions. Furthermore, the incorporation of heteroatoms can not only provide extra defects, but also contribute to redox reactions, which can facilitate the sodium ion storage. In 2017, sodium storage device based on graphdiyne nanosheets (GDY-NS) electrodes with good electronic conductivity and mechanical properties was designed for the first time by Wang and co-workers [42], as shown in Fig. 1a and b. Notably, the fabricated GDY-NS//AC based SICs illustrated excellent rate performance and long cycling lifespan, in which the capacitance still retained $>90 \%$ after 3000 cycles (Fig. 1c and $\mathrm{d}$ ). The SICs delivered an energy density of $182.3 \mathrm{~W} \mathrm{~h} \mathrm{~kg}^{-1}$ at the power density of $300 \mathrm{~W} \mathrm{~kg}^{-1}$ and $166 \mathrm{~W} \mathrm{~h} \mathrm{~kg}^{-1}$ at $15,000 \mathrm{~W} \mathrm{~kg}^{-1}$, which were much higher than that of carbon nanosheets//carbon nanosheets based devices [43]. The layered structure with intramolecular pores of GDY-NS electrode can greatly increase the active sites and promote the fast ion transfer for sodium-ion 

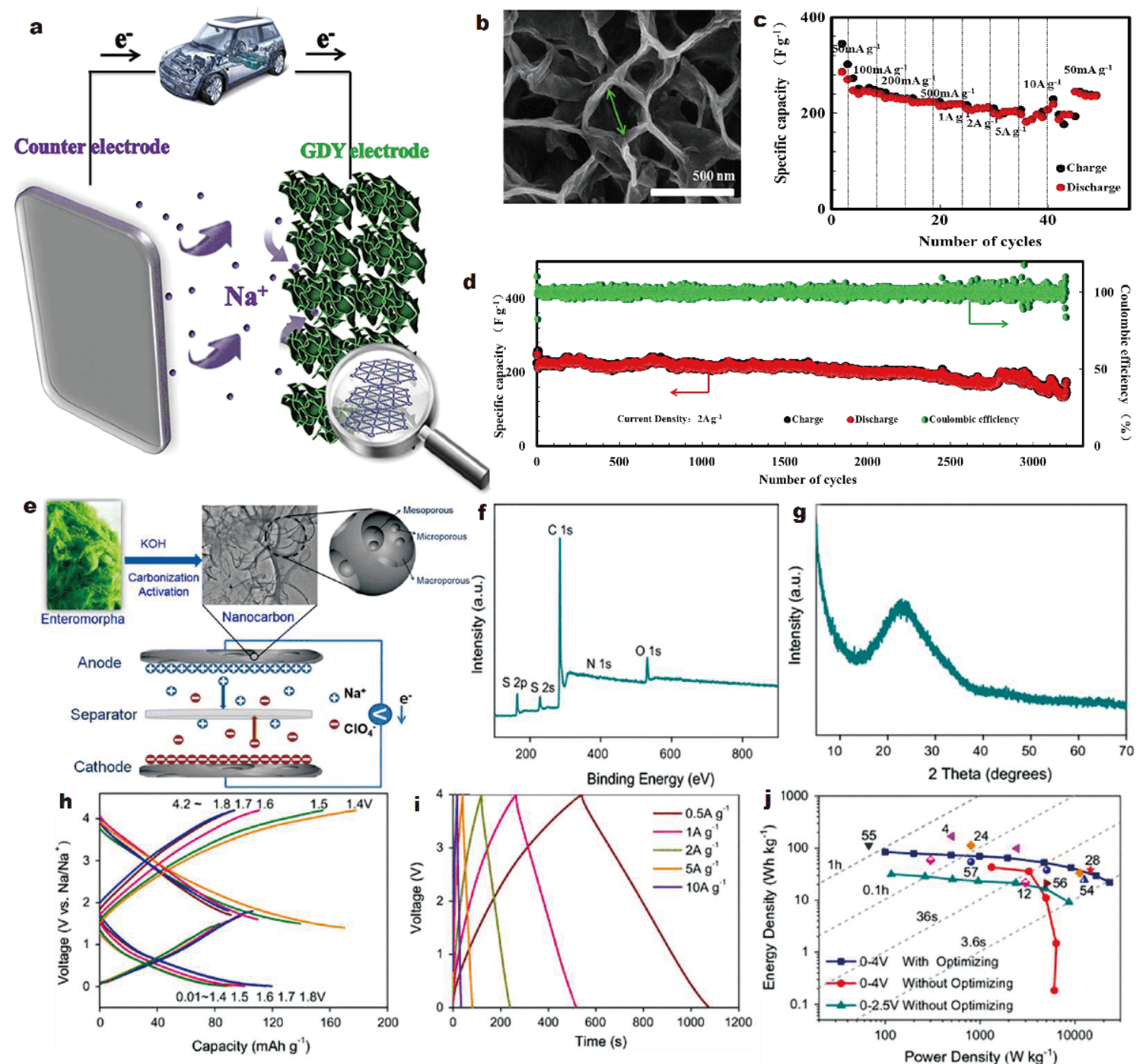

Figure 1 (a) Schematic diagram of the sodium-ion diffusion and sodiation in GDY-NS materials. (b) Top view SEM image of GDY-NS on the Cu substrate. (c) Rate performance of the GDY-NS//AC SICs at various current densities from $50 \mathrm{~mA} \mathrm{~g}^{-1}$ to $5 \mathrm{~A} \mathrm{~g}^{-1}$. (d) The cycling performance of the GDY-NS//AC SICs at the current density of $1 \mathrm{~A} \mathrm{~g} \mathrm{~g}^{-1}$. Reproduced with permission from [42]. Copyright 2017, American Chemical Society. (e) Schematic illustration of the preparation of EDHPC and the fabrication of EDHPC//EDHPC SICs. (f, g) XPS survey spectrum and XRD pattern of EDHPC. (h, i) Charge-discharge curves of two half cells and the EDHPC//EDHPC SICs. (j) Ragone plots of SICs. Reproduced with permission from [44]. Copyright 2018, Springer.

storage. Recently, Liu and co-workers [44] fabricated the symmetric SICs based on enteromorpha-derived hierarchical porous carbon(EDHPC) electrode materials with a 3D sponge-like network structure through simultaneous activation and carbonization process as shown in Fig. 1e. The X-ray diffraction (XRD) and X-ray photoelectron spectroscopy (XPS) results show that besides carbon, some other elements including $\mathrm{N}, \mathrm{O}$ and $\mathrm{S}$ also coexist in EDHPC electrode with the disordered structure (Fig. If and g). The presence of heteroatoms in EDHPC can be involved in surface redox reactions and introduce extra active and defective sites for additional charge accumulation. Encouragingly, the assembled SICs with the extended potential window of $0-4 \mathrm{~V}$ obtain the maximum energy density of $84 \mathrm{~W} \mathrm{~h} \mathrm{~kg}^{-1}$ and power density of $9053 \mathrm{~W} \mathrm{~kg}^{-1}$ as displayed in Fig. 1h-j. The EDHPC electrodes have the advantages of large specific surface area $\left(1968 \mathrm{~m}^{2} \mathrm{~g}^{-1}\right)$, hierarchical porosity and heteroatom doping, which are beneficial to improving the electrochemical performance. 


\section{Transition metal oxides and compounds}

Besides carbon materials, many transition metal oxides such as $\mathrm{V}_{2} \mathrm{O}_{5}, \mathrm{MnO}_{2}, \mathrm{Fe}_{3} \mathrm{O}_{4}, \mathrm{MoO}_{2}, \mathrm{Nb}_{2} \mathrm{O}_{5}$ and $\mathrm{TiO}_{2}$. $[45,56]$ with constructed nanostructures have been explored as pseudocapacitive anode materials, in which the disctinctive microstructures with sizable tunnels can reduce the diffusion pathways of the ions. As reported, the layer-structured $\mathrm{V}_{2} \mathrm{O}_{5}$ with large lattice distance of $9.5 \AA$ ((001) plane) has miscellaneous oxidation states, demonstrating obvious pseudocapacitive behavior. Nevertheless, the low electrical conductivity $\left(\sim 10^{-6} \mathrm{~S} \mathrm{~cm}^{-1}\right)$ limited the applications of $\mathrm{V}_{2} \mathrm{O}_{5}$ for high-performance SICs. In order to improve the electric conductivity of the electrode materials, constructing transition metal oxide composites with carbon materials is one of the most common approaches. For example, in 2012, Chen et al. [45] fabricated a SIC device using $\mathrm{V}_{2} \mathrm{O}_{5}$ /carbon nanotube (CNT) nanocomposite synthesized through one-pot hydrothermal process as anode and $\mathrm{AC}$ as cathode in $1 \mathrm{~mol} \mathrm{~L}^{-1} \mathrm{NaClO}_{4}$ organic electrolyte, which gave a maximum energy density of $38 \mathrm{~W} \mathrm{~h} \mathrm{~kg}^{-1}$ at a power density of $140 \mathrm{~W} \mathrm{~kg}^{-1}$ and a high power density of $5000 \mathrm{~W} \mathrm{~kg}^{-1}$ at an energy density of $7.5 \mathrm{~W} \mathrm{~h} \mathrm{~kg}^{-1}$, respectively. In this work, the CNTs can link the small $\mathrm{V}_{2} \mathrm{O}_{5}$ crystal domains and supply enhanced electronic conductivity, leading to an increased rate of charge transfer. In addition, $\mathrm{Nb}_{2} \mathrm{O}_{5}$ has been recognized as a promising anode material for LIBs due to its dominating pseudocapacitive properties and the large interlayer lattice spacing of $3.9 \AA$ ((001) plane). The self-assembled $\mathrm{Nb}_{2} \mathrm{O}_{5}$ NSs cluster anode and peanut shell carbon (PSC) cathode were used to fabricate SICs, which exhibited a high energy density $\left(43.2 \mathrm{~W} \mathrm{~h} \mathrm{~kg}^{-1}\right)$, high power density $\left(5760 \mathrm{~W} \mathrm{~kg}^{-1}\right)$ and a capacity retention of $80 \%$ after 3000 cycles [50]. Carbon material composited $\mathrm{Nb}_{2} \mathrm{O}_{5}$ electrodes can significantly improve the electrochemical performance of SICs. For example, in 2016, Lim et al. [51] presented a sodium-ion hybrid SCs using $\mathrm{Nb}_{2} \mathrm{O}_{5} @$ carbon core-shell nanoparticles combining with rGO nanocomposites as anode and MSP-20 as cathode, which delivered high energy/power density $\left(76 \mathrm{~W} \mathrm{~h} \mathrm{~kg}^{-1}\right.$ and $20,800 \mathrm{~W} \mathrm{~kg}^{-1}$ ) in the voltage of $1.0-4.3 \mathrm{~V}$. Recently, Wang and co-workers [52] prepared typical composited electrodes through directly growing ultrathin graphene shells over $\mathrm{T}-\mathrm{Nb}_{2} \mathrm{O}_{5}$ nanowires $\left(\mathrm{Gr}-\mathrm{Nb}_{2} \mathrm{O}_{5}\right)$ by plasma enhanced chemical vapor deposition (PECVD) as displayed in Fig. 2a and b. The synergistic effect between $\mathrm{Nb}_{2} \mathrm{O}_{5}$ nanowires and graphene shells has merits of shortening ion diffusion path and enhancing electronic conductivity of electrode. As a result, $61.2 \%$ of the total capacity of the $\mathrm{Gr}-\mathrm{Nb}_{2} \mathrm{O}_{5}$ electrode originated from surface capacitive effect at a small scan rate of $0.5 \mathrm{mV} \mathrm{s}^{-1}$. Fig. 2c further shows that $\sim 67 \mathrm{~W} \mathrm{~h} \mathrm{~kg}^{-1}$ of the energy density and above $97.1 \%$ of Coulombic efficiency can be maintained at $1 \mathrm{~A} \mathrm{~g}^{-1}$ after 1500 cycles, demonstrating that the SICs own a stable cycling performance. Meanwhile, the SIC devices of $\mathrm{Gr}-\mathrm{Nb}_{2} \mathrm{O}_{5} / / \mathrm{AC}$ delivered the maximum energy density of $\sim 112.9 \mathrm{~W} \mathrm{~h} \mathrm{~kg}^{-1}$ and the high power density of $\sim 5330 \mathrm{~W} \mathrm{~kg}^{-1}$ as shown in the inset of Fig. 2c. The unique core/shell structure of $\mathrm{Gr}-\mathrm{Nb}_{2} \mathrm{O}_{5}$ is beneficial to the electron and $\mathrm{Na}^{+}$transport, guaranteeing rapid pseudocapacitive reactions on the interface of $\mathrm{Nb}_{2} \mathrm{O}_{5}$ and electrolyte. In brief, the methods of combining with carbon materials and constructing special nanostructures can effectively improve sodium ion energy storage.

Ti-based oxides with low volume expansion and low voltage can be considered as hopeful anode materials for sodium-ion storage. Similarly, poor electron conductivity of the bulk $\mathrm{TiO}_{2}$ hinders its usage. As a consequence, many efforts have been made to improve the conductivity of the Ti-based oxides. For example, in 2017, Le et al. [54] synthesized single-crystal-like $\mathrm{TiO}_{2}$ anchored on graphene by microwave-assisted solvothermal method. In sodium ions half cells, around $73 \%$ of the capacity can be ascribed to the capacitive contributions at the scan rate of $3 \mathrm{mV} \mathrm{s}^{-1}$. The SICs connecting AC cathode show a high energy density of $64.2 \mathrm{~W} \mathrm{~h} \mathrm{~kg}^{-1}$ and high power density of $1357 \mathrm{~W} \mathrm{~kg}^{-1}$, as well as $90 \%$ of capacitance retention after 10,000 cycles. Meanwhile, another novel SICs using $\mathrm{TiO}_{2} @ \mathrm{CNT} @ \mathrm{C}$ nanorods as anode and biomass-derived carbon as cathode were fabricated in 2017 [55]. According to scanning electron microscopy (SEM) and high resolution transmission electron microscopy (HRTEM) images (Fig. $2 \mathrm{~d}$ and e), $\mathrm{TiO}_{2}$ nanomaterials and multiwall CNTs (MWCNTs) both exist in carbon nanorods. The maximum value of the capacitive contribution is $81 \%$ at the scan rate of $3 \mathrm{mV} \mathrm{s}^{-1}$ for the $\mathrm{TiO}_{2} @ \mathrm{CNT} @ \mathrm{C}$, indicating that a large proportion of the capacity originates from the surface-controlled pseudocapacitance. Due to the improved electrical conductivity in the presence of MWCNTs, the SICs can obtain an exceptionally high energy and power densities of $81.2 \mathrm{~W} \mathrm{~h} \mathrm{~kg}^{-1}$ and $12,400 \mathrm{~W} \mathrm{~kg}^{-1}$ in the potential window of $1.0-4.0 \mathrm{~V}$ as displayed in the Fig. 2f. Moreover, the fabricated SICs achieve $85.3 \%$ of the capacitance retention after 5000 cycles. This work offers a method to improve the conductivity of the $\mathrm{TiO}_{2}$ by incorporating MWCNTs. Besides the approach of making composites with conductive materials, narrowing the band gap of the electrodes can 

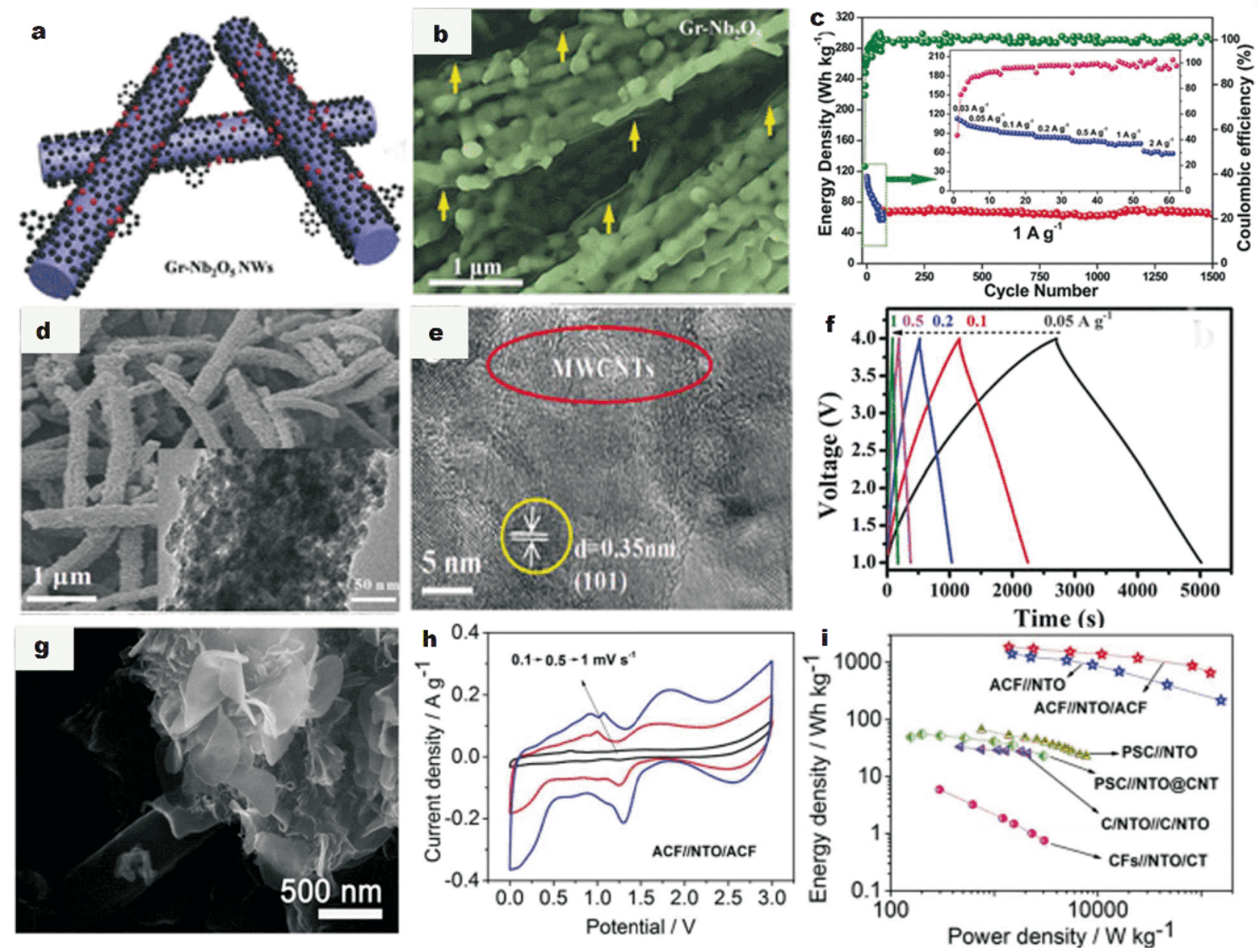

Figure 2 (a) Schematic illustration of $\mathrm{Gr}-\mathrm{Nb}_{2} \mathrm{O}_{5}$ composites. (b) SEM image of $\mathrm{Gr}-\mathrm{Nb}_{2} \mathrm{O}_{5}$ composites. (c) The long-term cycling performance of the $\mathrm{Gr}^{-\mathrm{Nb}_{2}} \mathrm{O}_{5} / / \mathrm{AC}$ SICs at $1 \mathrm{~A} \mathrm{~g}^{-1}$. The inset shows the rate capability of the SICs at various current densities from 0.03 to $2 \mathrm{~A} \mathrm{~g}^{-1}$. Reproduced with permission from [52]. Copyright 2018, Wiley-VCH. (d, e) SEM and HRTEM images of $\mathrm{TiO}_{2} @ \mathrm{CNT} @ \mathrm{C}$. (f) Charge-discharge curves of TiO $@$ CNT@C//BAC SICs at various current densities in the potential of 1-4 V. Reproduced with permission from [55]. Copyright 2017, Wiley-VCH. (g) Field emission SEM (FESEM) image of NTO/ACF nanocomposite. (h) Cyclic voltammetry (CV) curves of the ACF//NTO/ACF SICs at different current densities. (i) Ragone plots compared with other reports. Reproduced with permission from [63]. Copyright 2018, Royal Society of Chemistry.

also remarkably improve the electric conductivity. In 2018, Babu et al. [56] reported semicrystalline brown $\mathrm{TiO}_{2}$ nanotubes (BTNT) with $\mathrm{Ti}^{3+}$ by a hydrothermal route, which can enhance conductivity through shortening the colossal band gap. Through the kinetics studies, $57 \%$ of the total charge was surface capacitive contribution in the BTNT electrode at a scan rate of $1 \mathrm{mV} \mathrm{s}^{-1}$, which was higher than crystalline dark brown $\mathrm{TiO}_{2}(47 \%)$ in the same work. And the fabricated BTNT//AC device achieved a maximum energy density about $68 \mathrm{~W} \mathrm{~h} \mathrm{~kg}^{-1}$, a high power density around $12,500 \mathrm{~W} \mathrm{~kg}^{-1}$ and a good cycling performance with $80 \%$ capacitance retention up to 10,000 cycles.

$\mathrm{Na}_{2} \mathrm{Ti}_{3} \mathrm{O}_{7}$ (NTO), one kind of Ti-based compound, has recently been extensively explored owing to its rich reserves, low toxicity and high theoretical capacity of
$310 \mathrm{~mA} \mathrm{~h} \mathrm{~g}^{-1}$. In particular, NTO possesses the lowest voltage $\left(0.3 \mathrm{~V} v s . \mathrm{Na}^{+} / \mathrm{Na}\right)$, demonstrating that it can be a promising candidate as anode material for SICs [57-61]. For example, in 2016, Li and co-workers [62] reported a quasi-solid-state SIC with urchin-like NTO as anode prepared by hydrothermal reaction and peanut shell derived carbon as cathode, using $\mathrm{Na}^{+}$ions conducting gel polymer as electrolyte. The high energy and power densities can reach $111.2 \mathrm{~W} \mathrm{~h} \mathrm{~kg}^{-1}$ and $11,200 \mathrm{~W} \mathrm{~kg}^{-1}$, respectively. Recently, Qiu et al. [63] reported the in situ fabrication of NTO NSs on the AC fiber (ACF) through electrospinning, one-pot carbonization, activation and subsequently the hydrothermal process (Fig. 2g). The electrochemical measurements of the SICs were performed in the potential range of $0-3 \mathrm{~V}$ (Fig. $2 \mathrm{~h}$ and i). The Ragone plots of SICs based on NTO/ACF//ACF 
electrodes showed a high energy density of 127.73 $\mathrm{W} \mathrm{h} \mathrm{kg}^{-1}$ at the power density of $95.79 \mathrm{~W} \mathrm{~kg}^{-1}$, higher than that of ACF//NTO and other SCs based on NTO electrodes $[58,60,62,64]$. The surface-controlled capacitance ratio of NTO/ACF nanocomposites was higher than that of the pure NTO at the same scan rates because of the electric double layer capacitor behavior of the ACF. With the aid of ACF, the transportation and diffusion of $\mathrm{Na}^{+}$can be enhanced. Simultaneously, the structural stability and electronic conductivity of the electrode materials would also be highly improved. In addition, spinel $\mathrm{NiCo}_{2} \mathrm{O}_{4}$ was involved in SICs as anode material and exhibited good electrochemical performance. Yang et al. [65] prepared the SICs device by employing pre-sodiated $\mathrm{NiCo}_{2} \mathrm{O}_{4}$ as anode and $\mathrm{AC}$ as cathode. During the reaction, the pre-sodiated $\mathrm{NiCo}_{2} \mathrm{O}_{4}$ electrodes converted to $\mathrm{Na}_{2} \mathrm{O}$, metallic $\mathrm{Ni}$ and $\mathrm{Co}$, which were kinetically beneficial to fast interfacial electrochemical reactions. The SICs delivered the maximum energy and power densities of $120.3 \mathrm{~W} \mathrm{~h} \mathrm{~kg}^{-1}$ and $10,000 \mathrm{~W} \mathrm{~kg}^{-1}$, respectively, which were 5-9 times higher than other SICs based on $\mathrm{NiCo}_{2} \mathrm{O}_{4}$ without pre-sodiation [66].

\section{Transition metal chalcogenides and nitrides}

Transition metal sulfides $\left(\mathrm{MoS}_{2}\right.$ and $\left.\mathrm{SnS}_{2}\right)$ with layered structure and large interplanar distance have been applied in energy storage devices in recent years [67-70]. However, the poor inherent electronic conductivity causes serious polarization and low electrode utilization efficiency. Consequently, optimizing the nanostructure and enhancing the conductivity of the transition metal sulfides are vital and effective to achieve high pseudocapacitive charge storage. For example, the layered $\mathrm{SnS}_{2}$ has a large interlayer spacing of $0.59 \mathrm{~nm}$ in favor of the insertion/extraction of $\mathrm{Na}^{+}$. In 2016, Chauhan et al. [68] synthesized $\mathrm{SnS}_{2} / \mathrm{RGO}$ NSs under in situ hydrothermal conditions. The fabricated symmetric $\mathrm{SnS}_{2} / \mathrm{RGO} / / \mathrm{SnS}_{2} /$ RGO hybrid capacitor in $\mathrm{Na}_{2} \mathrm{SO}_{4}$ solution exhibited a specific capacitance of $500 \mathrm{~F} \mathrm{~g}^{-1}$, energy density of 16.67 $\mathrm{W} \mathrm{h} \mathrm{kg}^{-1}$ and power density of $488 \mathrm{~W} \mathrm{~kg}^{-1}$. The 2D layered structure, enhanced electron mobility and synergistic effect of graphene sheets with $\mathrm{SnS}_{2} \mathrm{NSs}$ led to good energy storage performance of the electrode material. Similar to $\mathrm{SnS}_{2}$, in 2017, Wang et al. [69] prepared monolayer $\mathrm{MoS}_{2}$-carbon $\left(\mathrm{MoS}_{2}-\mathrm{C}\right)$ composites with expanded interlayer spacing from 0.62 to $0.98 \mathrm{~nm}$ through atomic interface modification method. The pseudocapacitive contribution ratio of the $\mathrm{MoS}_{2}-\mathrm{C}$ electrode was $76.7 \%$ at $5 \mathrm{mVs}^{-1}$. More importantly, the SICs were prepared with $\mathrm{MoS}_{2}-\mathrm{C}$ as anode and polyaniline derived porous carbon (PDPC) as cathode in $1 \mathrm{~mol} \mathrm{~L}^{-1} \mathrm{NaClO}_{4}$ electrolyte, which can get a maximum energy density of $111.4 \mathrm{~W} \mathrm{~h} \mathrm{~kg}^{-1}$, a high power density of $12,000 \mathrm{~W} \mathrm{~kg}$ and a good capacitance retention of $77.3 \%$ for 10,000 cycles. Zhao and co-workers [70] also reported an enhanced sodium storage capability enabled by $\mathrm{MoS}_{2}$ supported on carbon fibers (E-MoS $/$ carbon fibers) with a wide interlayer spacing of $1.34 \mathrm{~nm}$ (Fig. 3a and b), which was almost twice as large as that of the commercial $\mathrm{MoS}_{2}$ in 2017. In addition, the structural model of the E-MoS $/$ carbon fibers in Fig. $3 c$ was in accordance with the HRTEM result. At the scan rate of $2 \mathrm{mV} \mathrm{s}^{-1}$, the capacitive contribution can reach up to $89.4 \%$. Based on E$\mathrm{MoS}_{2}$ /carbon fibers as anode and commercial AC as cathode, the SICs can operate under the potential range from 1.0 to $4.3 \mathrm{~V}$ in $1 \mathrm{~mol} \mathrm{~L}^{-1} \mathrm{NaClO}_{4}$ electrolyte and deliver the high energy density of $54.9 \mathrm{~W} \mathrm{~h} \mathrm{~kg}^{-1}$ as shown in Fig. 3d. The special structure of E- $\mathrm{MoS}_{2} /$ carbon fibers with the features of shortened ion diffusion pathways, enhanced electron transfer and easily accessible active sites was conducive to improving the capacitive contribution of the electrode materials and the electrochemical performance of SICs.

As an analogue to transition metal sulfides, transition metal selenides have also attracted research attention in SICs. For example, $\mathrm{MoSe}_{2}$ with the features of layered structure, large interlayer distance $(0.64 \mathrm{~nm})$, narrow band gap $(1.1 \mathrm{eV})$ and high theoretical capacity (422 $\mathrm{mA} \mathrm{h} \mathrm{g}^{-1}$ ) stands out from various candidates [71]. However, the issues of intrinsic inferior electronic conductivity and big volume change hinder the usage of $\mathrm{MoSe}_{2}$. To solve these problems, Zhao et al. [72] designed ordered $\mathrm{MoSe}_{2}$ /graphene nanocomposite through hydrothermal method in 2018. The $\mathrm{MoSe}_{2}$ NSs can produce enough open space to accommodate the volume changes during Na-ion insertion/extraction. Furthermore, the graphene not only improved the electrical conductivity of the materials, but also kept the $\mathrm{MoSe}_{2} \mathrm{NSs}$ from aggregation. Meanwhile, the Mo-C chemical bonding can significantly enhance the charge transfer in the electrode material. The assembled $\mathrm{MoSe}_{2} /$ graphene//AC SICs showed good cycling stability at $5 \mathrm{~A} \mathrm{~g}^{-1}$ for 5000 cycles with a high energy and power density of $82 \mathrm{~W} \mathrm{~h} \mathrm{~kg}^{-1}$ and $10,752 \mathrm{~W} \mathrm{~kg}^{-1}$, respectively. Similarly, a method of in situ growing $\mathrm{CoSe}_{2} @ v e r t i c a l l y-o r i e n t e d$ graphene hierarchical architecture on carbon cloth (CoSe $\left.e_{2} @ V G / C C\right)$ through PECVD and wet chemistry was reported by Xia and coworkers in 2019 [73]. This electrode with superstructure can be prepared without binders/additives and beneficial 

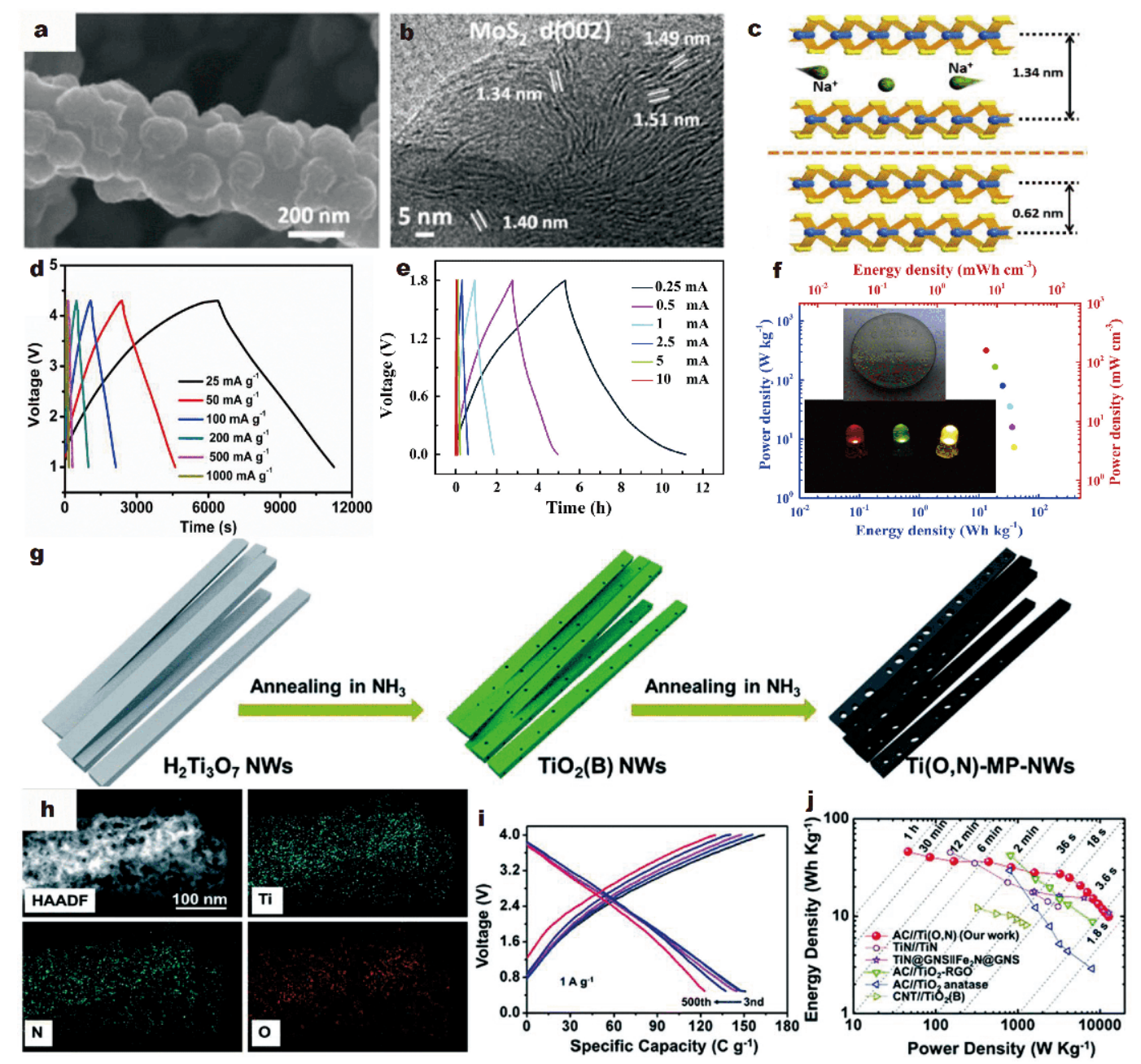

Figure 3 (a, b) SEM and HRTEM images of the E-MoS 2 /carbon fibers. (c) Structural models of the $\mathrm{MoS}_{2}$ with different interlayer spacings. (d) GCD curves of the $\mathrm{E}-\mathrm{MoS}_{2} /$ carbon fibers//AC SICs at various current densities. Reproduced with permission from [70]. Copyright 2017, Elsevier. (e) GCD curves of the VN-MWCNT//MnO ${ }_{2}-\mathrm{MWCNT}$ SICs at different currents. (f) Ragone plot of the hybrid SICs. The insets display the VN-MWCNT// $\mathrm{MnO}_{2}-\mathrm{MWCNT}$ coin cell that used for tests and powering LED bulbs. Reproduced with permission from [75]. Copyright 2014, Elsevier. (g) Schematic of the synthesis process for $\mathrm{Ti}(\mathrm{O}, \mathrm{N})-\mathrm{MP}-\mathrm{NWs}$. (h) Elemental mapping images of $\mathrm{Ti}(\mathrm{O}, \mathrm{N})-700$. (i) The cycling performance of the Ti(O,N)//AC SICs. (j) Ragone plots of various supercapacitors. Reproduced with permission from [76]. Copyright 2017, Royal Society of Chemistry.

to fast electron/ion diffusion. The fabricated $\mathrm{CoSe}_{2} @ \mathrm{VG} /$ $\mathrm{CC} / / \mathrm{AC}$ SICs delivered a high energy and power density of $116 \mathrm{~W} \mathrm{~h} \mathrm{~kg}^{-1}$ and $7298 \mathrm{~W} \mathrm{~kg}^{-1}$, respectively.

Due to superior electronic conductivity and high pseudocapacitance, the transition metal nitrides are considered as promising electrodes, especially, the $\mathrm{VN}$ and TiN [74-76]. For example, in 2015, Su and coworkers [75] developed a hybrid SC with VN-MWCNT negative electrode and $\mathrm{MnO}_{2}$-MWCNT positive electrode in $\mathrm{Na}_{2} \mathrm{SO}_{4}$ electrolyte, operated under the potential of $0-1.8 \mathrm{~V}$ as displayed in the Fig. 3e. The galvanostatic charge/discharge (GCD) curves displayed nearly triangle shape with good Coulombic efficiency. Meanwhile, the potential drops were not obvious at low currents, demonstrating that the internal resistance of the device was very low. After 1000 cycles, the capacitance retention retained $80 \%$, suggesting a good cycling performance of the SICs. Fig. 3f exhibited the maximum energy and power densities of $38.7 \mathrm{~W} \mathrm{~h} \mathrm{~kg}^{-1}\left(19.4 \mathrm{~mW} \mathrm{~h} \mathrm{~cm}^{-3}\right)$ and $316.2 \mathrm{~W} \mathrm{~kg}^{-1}$ (158.1 mW cm $\mathrm{cm}^{-3}$ ), respectively. Inset of Fig. $3 \mathrm{f}$ shows that three light-emitting diode (LED) bulbs can be simultaneously lighted by VN-MWCNT// $\mathrm{MnO}_{2}-$ MWCNT coin cells. Furthermore, in 2017, Dong et al. [76] synthesized titanium oxynitride mesoporous nanowires $(\mathrm{Ti}(\mathrm{O}, \mathrm{N})-\mathrm{MP}-\mathrm{NWs})$ with tunable $\mathrm{O} / \mathrm{N}$ ratios based on an anion exchange process in Fig. 3g. A large number 
of holes occurred in the whole course that can be beneficial to contact with the $\mathrm{NaClO}_{4}$ organic electrolyte. The capacitive contribution of the $\mathrm{Ti}(\mathrm{O}, \mathrm{N})-700$ in sodium ion half cell was about $78.9 \%$ at $2 \mathrm{mV} \mathrm{s}^{-1}$. Elemental mappings in Fig. 3h states that the sample consists of Ti, N and O. Before assembling SICs device, the $\mathrm{Ti}(\mathrm{O}, \mathrm{N})$-MPNWs were pre-sodiated for two cycles. Fig. $3 i$ shows the charge/discharge curves of the SICs in the voltage of $0.5-4 \mathrm{~V}$, achieving a specific capacity of $56 \mathrm{C} \mathrm{g}^{-1}$ at $1 \mathrm{~A} \mathrm{~g}^{-1}$. The maximum energy and power densities of the $\mathrm{Ti}(\mathrm{O}, \mathrm{N})-\mathrm{MP}-\mathrm{NWs} / / \mathrm{AC}$ device were $46 \mathrm{~W} \mathrm{~h} \mathrm{~kg}^{-1}$ and $11,500 \mathrm{~W} \mathrm{~kg}^{-1}$ (Fig. 3j), higher than that of previously reported similar SIC devices including TiN//TiN, AC// $\mathrm{TiO}_{2}-\mathrm{rGO}, \mathrm{TiN} @ \mathrm{GNS} / / \mathrm{Fe}_{2} \mathrm{~N} @ \mathrm{GNS}, \mathrm{CNT} / / \mathrm{TiO}_{2}(\mathrm{~B})$, and $\mathrm{AC} / / \mathrm{TiO}_{2}$ (anatase) [5,77-79]. The features of excellent conductive nature, largely increased surface reaction sites and short ion diffusion pathways of the $\mathrm{Ti}(\mathrm{O}, \mathrm{N})$-MPNWs demonstrate the $\mathrm{Ti}(\mathrm{O}, \mathrm{N})-\mathrm{MP}-\mathrm{NWs}$ can be prospectively used as the electrode in SICs.

\section{MXenes}

2D MXenes discovered in 2011 are a hot issue with fewatom layered structures that can be reversibly inserted/ extracted with foreign cations as anode materials in SICs. The formula of MXenes is $\mathrm{M}_{n+1} \mathrm{X}_{n} \mathrm{~T}_{n}$, where $\mathrm{M}$ represents the transition metal ( $\mathrm{Ti}, \mathrm{V}, \mathrm{Nb}, \mathrm{Ta}, \mathrm{Cr}, \mathrm{Mo}$ ), $\mathrm{X}$ is $\mathrm{C}$ and/or
$\mathrm{N}, \mathrm{T}$ is the surface function group $(-\mathrm{OH},-\mathrm{F},-\mathrm{O})$, and $n=$ 1,2 or 3 [80]. In the past few years, many studies referred to MXenes as anode materials in SICs due to the expanded $d$-spacing through selectively etching and further activation processes. For example, in 2014, Wang et al. [81] synthesized $\mathrm{Ti}_{2} \mathrm{CT}_{x}$ with expanded interlayer distance of $7.7 \AA$ (initial value of $6.8 \AA$ ) via etching in $\mathrm{HF}$ aqueous solution. Then, the intercalation of $\mathrm{Na}^{+}$in the $\mathrm{Ti}_{2} \mathrm{CT}_{x}$ sheets resulted in the interlayer distance further enlarging to $10.1 \AA$ by the first cathodic reaction (Fig. 4a). The $d$-spacing can keep unchanged in the following charge/discharge process, illustrating that the reaction mechanism was based on pseudocapacitance. In addition, HRTEM results also confirmed the change of $d$-spacing in $\mathrm{Ti}_{2} \mathrm{CT}_{x}$ after reactions (Fig. $4 \mathrm{~b}$ and c). The prepared $\mathrm{Ti}_{2} \mathrm{CT}_{x} / / \mathrm{Na}_{2} \mathrm{Fe}_{2}\left(\mathrm{SO}_{4}\right)_{3}$ SIC devices showed extremely stable efficiency and cycling properties after the initial cycles, ascribed to the pseudocapacitance behavior of the MXene material as shown in Fig. 4d. A high energy density of $260 \mathrm{~W} \mathrm{~h} \mathrm{~kg}^{-1}$ at high specific power density of $1400 \mathrm{~W} \mathrm{~kg}^{-1}$ can be obtained based on the weight of $\mathrm{Ti}_{2} \mathrm{CT}_{x}$. Furthermore, the prepared $\mathrm{Ti}_{3} \mathrm{C}_{2} \mathrm{~T}_{x}$ using in situ $\mathrm{HF}$ formation etchants ( $\mathrm{LiF}$ and $\mathrm{HCl}$ ) has high electrical conductivity, large flake sizes, environmental stability and good mechanical properties. In 2016, Xie et al. [80] mixed the $\mathrm{Ti}_{3} \mathrm{C}_{2} \mathrm{~T}_{x}$ (negatively charged) and the CNTs (positively

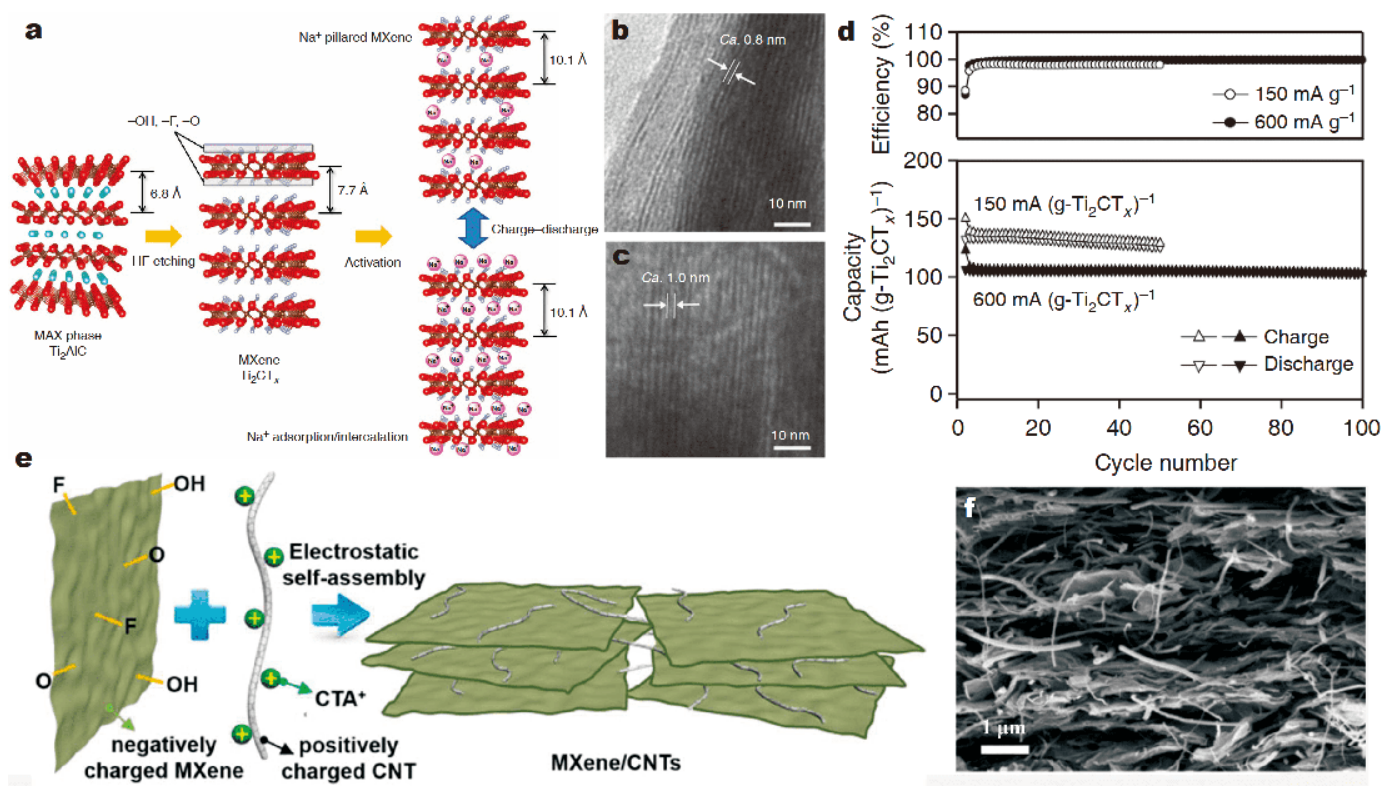

Figure 4 (a) Schematic illustration of the reaction mechanism of $\mathrm{Ti}_{2} \mathrm{CT}_{x}$ by electrochemical activation. (b, c) TEM images of the pristine $\mathrm{Ti}_{2} \mathrm{CT}_{x}$ and activated $\mathrm{Ti}_{2} \mathrm{CT}_{x}$ after the first cycle. (d) The cycling stability and Coulombic efficiency of the $\mathrm{Ti}_{2} \mathrm{CT}_{x} / \mathrm{Na}_{2} \mathrm{Fe}_{2}\left(\mathrm{SO}_{4}\right)_{3}$ SICs in the voltage of $0.1-3.8 \mathrm{~V}$. Reproduced with permission from [81]. Copyright 2015, Macmillan Publishers Limited. (e) Schematic diagram of the self-assembly preparation of $\mathrm{Ti}_{3} \mathrm{C}_{2} \mathrm{~T}_{x} / \mathrm{CNT}$. (f) Cross-section SEM image of porous $\mathrm{Ti}_{3} \mathrm{C}_{2} \mathrm{~T}_{x} / \mathrm{CNT}$. Reproduced with permission from [80]. Copyright 2016, Elsevier. 
charged) to prepare porous self-assembled $\mathrm{Ti}_{3} \mathrm{C}_{2} \mathrm{~T}_{x} / \mathrm{CNT}$ $\left(\mathrm{Ti}_{3} \mathrm{C}_{2} \mathrm{~T}_{x} /\right.$ CNT-SA) by electrostatic interaction, in which the interspersed CNTs can significantly avert the MXene NSs restacking in Fig. 4e and f. More importantly, the $d$ spacing of the $\mathrm{Ti}_{3} \mathrm{C}_{2} \mathrm{~T}_{x} / \mathrm{CNT}$-SA was $16.4 \AA$ calculated from the XRD diffraction peak location, supplying channels for $\mathrm{Na}$ ions transport. Meanwhile, compared with the initial $\mathrm{Ti}_{3} \mathrm{C}_{2} \mathrm{~T}_{x}\left(19.6 \mathrm{~m}^{2} \mathrm{~g}^{-1}\right)$, the $\mathrm{Ti}_{3} \mathrm{C}_{2} \mathrm{~T}_{x} / \mathrm{CNT}$ SA composites had increased specific surface area of $185.4 \mathrm{~m}^{2} \mathrm{~g}^{-1}$ with much more active sites for electrochemical reactions. According to the kinetics calculation, the non-diffusion limited current was $88.1 \%$ of the whole charge at the scan rate of $0.1 \mathrm{mV} \mathrm{s}^{-1}$, demonstrating that the open structure of the $\mathrm{Ti}_{3} \mathrm{C}_{2} \mathrm{~T}_{x} /$ CNT-SA was beneficial to electrolyte diffusion. For the SICs assembled based on $\mathrm{Ti}_{3} \mathrm{C}_{2} \mathrm{~T}_{x} / \mathrm{CNT}$-SA anode and $\mathrm{Na}_{0.44} \mathrm{MnO}_{2}$ cathode, the first and $60^{\text {th }}$ discharge capacities were 286 and $242 \mathrm{~mA} \mathrm{~cm}^{-3}$ at the current density of $50 \mathrm{~mA} \mathrm{~g}^{-1}$, respectively, indicating a relatively stable cycling performance of the devices. This study provides a simple and efficient strategy to enhance the accessibility of MXenes to liquids or gases, which is expected to facilitate the applications of the MXenes in batteries, SCs, sensors, catalysis, etc. Recently, Kurra and co-workers [82] filtered multilayered $\mathrm{Ti}_{3} \mathrm{C}_{2} \mathrm{~T}_{x}$ electrode material on the top of delaminated $\mathrm{Ti}_{3} \mathrm{C}_{2} \mathrm{~T}_{x}$ as current collectors due to its high conductivity up to $5000 \mathrm{~S} \mathrm{~cm}^{-1}$. Moreover, the $d$-spacing of the multilayered $\mathrm{Ti}_{3} \mathrm{C}_{2} \mathrm{~T}_{x}$ was enlarged from 9.6 to $12.9 \AA$ because of the similar pillaring effect of $\mathrm{Na}^{+}$insertion in the initial cycles. In this work, authors developed a new method of fabricating the self-standing and additive-free bistacked MXene electrodes, leading to a major improvement of energy density per entire device due to the elimination of excess weight with no energy storage ability.

\section{NASICON}

NASICON with impressive features of high ion conductivity, stable structural framework and good thermal stability can be used in many fields, such as LIBs, Na-ion batteries, hybrid capacitors, solid electrolytes, gas sensors, etc. Generally, the chemical formula of NASICON materials is $\mathrm{Na}_{x} \mathrm{MM}^{\prime}\left(\mathrm{XO}_{4}\right)_{3}\left(\mathrm{M} / \mathrm{M}^{\prime}=\mathrm{Ti}, \mathrm{V}, \mathrm{Nb}, \mathrm{Fe}\right.$ or $\mathrm{Tr}$; $\mathrm{X}=$ $\mathrm{P}$ or $\mathrm{S} ; x=0,1,2,3$ or 4 ) [83]. Among these materials, $\mathrm{Na}_{3} \mathrm{~V}_{2}\left(\mathrm{PO}_{4}\right)_{3} \quad\left(\mathrm{~V}^{3+} / \mathrm{V}^{4+}\right.$ and $\mathrm{V}^{2+} / \mathrm{V}^{3+}$ redox conversion plateaus at 3.4 and $1.6 \mathrm{~V})$ and $\mathrm{NaTi}_{2}\left(\mathrm{PO}_{4}\right)_{3}\left(\mathrm{Ti}^{3+} / \mathrm{Ti}^{4+}\right.$ conversion voltage at $2.1 \mathrm{~V}$ ) with $3 \mathrm{D}$ framework structure comprising with corner-linked $\mathrm{Ti} / \mathrm{VO}_{6}$ octahedral and $\mathrm{PO}_{4}$ tetrahedral have been reported for hybrid SCs [8488]. Typically, depending on the operated platform po- tential, $\mathrm{Na}_{3} \mathrm{~V}_{2}\left(\mathrm{PO}_{4}\right)_{3}$ can be employed as both anode and cathode, but $\mathrm{NaTi}_{2}\left(\mathrm{PO}_{4}\right)_{3}$ generally acts as anode in SICs. Although the NASICON materials have many advantages, they possess poor electronic conductivity. Many researchers have made great efforts in order to solve this problem in the past few years. For example, in 2016, Thangavel et al. [89] reported SICs with carbon coated $\mathrm{Na}_{3} \mathrm{~V}_{2}\left(\mathrm{PO}_{4}\right)_{3}$ (C-NVP) as anode and AC derived from cinnamon sticks (CDCs) as cathode. HRTEM image in Fig. $5 \mathrm{a}$ demonstrates that the NVP is covered with a layer of carbon, which can facilitate the electrons to transfer into the C-NVP. Fig. $5 \mathrm{~b}$ and $\mathrm{c}$ show that the capacitance of the SICs still retained $95 \%$ after 10,000 cycles with the maximum specific capacity of $52.58 \mathrm{~F} \mathrm{~g}^{-1}$ in the voltage of $0-3 \mathrm{~V}$. Moreover, the Nyquist plots in the initial state and after 10,000 cycles displayed that the contact resistance between the electrode materials and electrolyte increased due to side reactions. But the charge transfer resistance decreased a little after 10,000 cycles, illustrating that the framework was stable and still practicable for reversible ions insertion (Fig. 5d). In 2017, Thangavel and coworkers [90] also reported $\mathrm{NaTi}_{2}\left(\mathrm{PO}_{4}\right)_{3}$ anchored on graphene nanosheets (GNTP) composite electrode material. TEM image in Fig. 5e demonstrates that the $\mathrm{NaTi}_{2}\left(\mathrm{PO}_{4}\right)_{3}$ particles are connected well with the graphene NSs (GNS) layers. When the SICs based on GNTP as anode and GNS as cathode were prepared and tested, $\mathrm{Na}^{+}$ions intercalated into the GNTP and $\mathrm{ClO}_{4}{ }^{-}$anions quickly adsorbed on the surface of GNS during the process of charging. On the contrary, $\mathrm{Na}^{+}$ions de-intercalated from the GNTP and $\mathrm{ClO}_{4}^{-}$anions desorbed from the GNS in the discharge process (Fig. 5f). The irregular triangular GCD curves declared that there were two storage mechanisms in the SICs (Fig. 5g). Furthermore, the SICs with a low performance degradation of $\sim 0.13 \%$ after 1000 cycles provided a maximum power density of $8000 \mathrm{~W} \mathrm{~kg}^{-1}$, higher than other reported hybrid capacitors as shown in Fig. 5h [5,91-96]. In the work, the presence of GNS can reduce the interfacial charge transfer resistance and buffer volume changes during the sodium ion insertion into the structure, resulting in good stability of the device.

\section{Alloys}

Alloys with large theoretical capacities and high electronic conductivity superiorities have attracted much attention for many years. However, the problem of severe pulverization urgently needs to be solved. In order to optimize the properties, Yuan and co-workers [97] prepared 3D porous networks of $\mathrm{NaBi}$ anode by pre-sodiating the $\mathrm{Bi}$ 

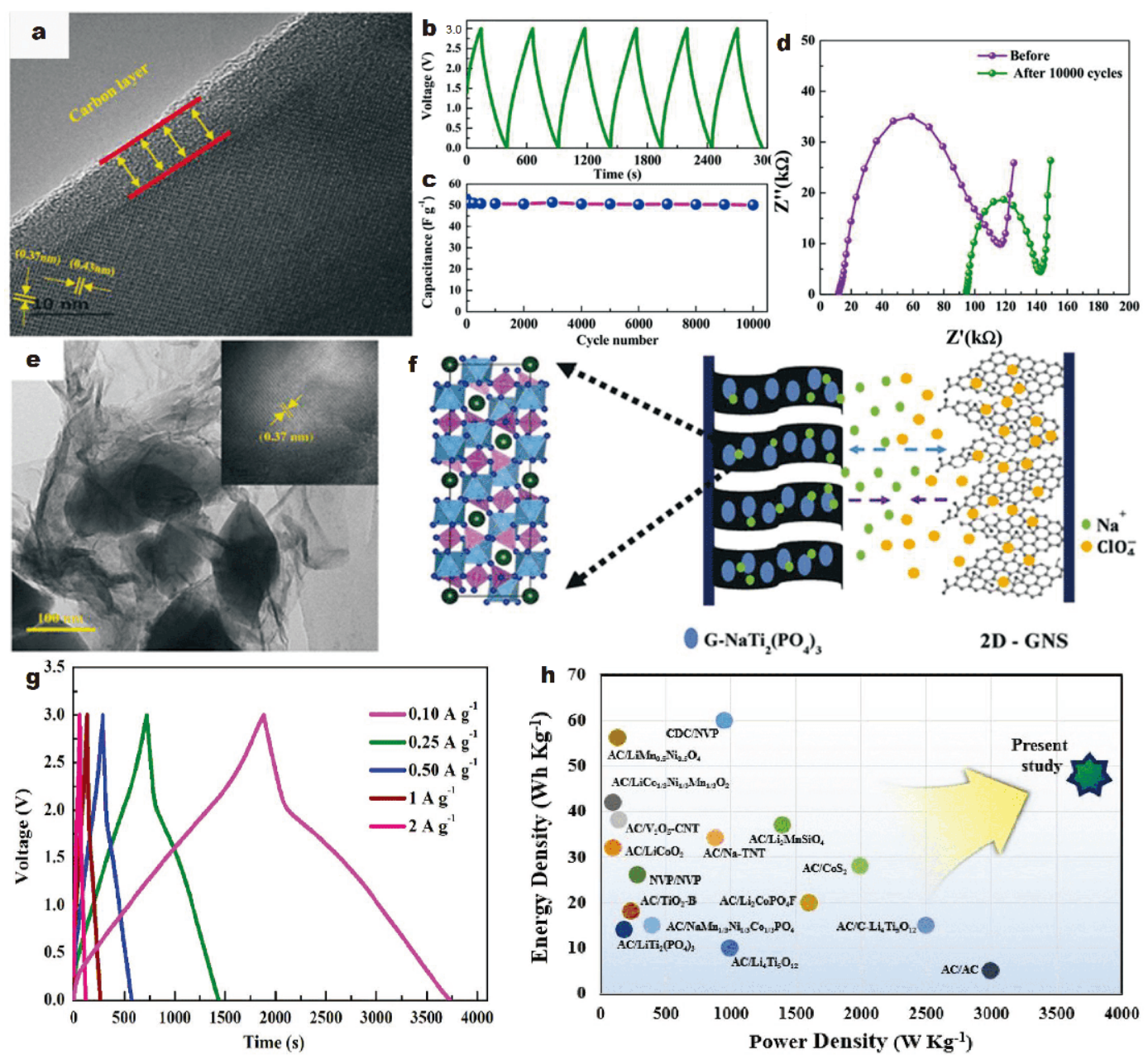

Figure 5 (a) HRTEM image of C-NVP. (b, c) GCD curves and cycling performance of the C-NVP//CDCs SICs. (d) Nyquist plots of the SICs before and after 10,000 cycles between 200 and $100 \mathrm{MHz}$. Reproduced with permission from [89]. Copyright 2016, Wiley-VCH. (e) TEM image of GNTP. The inset shows the HRTEM image of GNTP. (f) Operating mechanism of the GNTP//GNS SICs. (g) GCD curves at various current densities. (h) Comparison of the GNTP//GNS SICs performance with other systems. Reproduced with permission from [90]. Copyright 2017, Wiley-VCH.

raw material in $\mathrm{Na}$-ion half cell system during the first 10 cycles in 2018. The fabricated NaBi//AC SICs showed good capacity retention of $98.6 \%$ even cycling after 1000 times as well as high energy and power densities (106.5 $\mathrm{W} \mathrm{h} \mathrm{kg}^{-1}$ and $11,100 \mathrm{~W} \mathrm{~kg}^{-1}$ ) in $1.5 \mathrm{~mol} \mathrm{~L}^{-1} \mathrm{NaPF}_{6}$ diglyme-based electrolyte. The authors also investigated the $\mathrm{Na}^{+}$storage mechanism: the $\mathrm{NaBi}$ anode went through the process of $\mathrm{NaBi} \rightarrow \mathrm{Na}_{3} \mathrm{Bi}$ in the first charge process and $\mathrm{Na}_{3} \mathrm{Bi} \rightarrow \mathrm{NaBi} \rightarrow \mathrm{Bi}$ in the following discharge step, and then referred to the reversible reactions of $\mathrm{Bi} \leftrightarrow \mathrm{NaBi} \leftrightarrow \mathrm{Na}_{3} \mathrm{Bi}$. Specially, the volume expansion of the anode was significantly reduced due to the formation of porous $\mathrm{NaBi}$ architecture (from 256\% to $65.3 \%$ ), which can obviously shorten the ion diffusion distance, mitigate volume change and thus favor the re- action kinetics.

\section{Capacitor-type cathode materials}

\section{Carbon materials}

To our best knowledge, the energy storage mechanism of the capacitor-type cathode is usually the adsorption/desorption on the surface of porous materials based on anions. Carbon materials with large specific surface area are used more often in the research of SICs, such as graphene and AC $[27,30,36,43,47,53-55,59,63,65,66,70,72,76,82,84$, 96-100]. For example, Wang et al. [101] fabricated a quasi-solid-state SIC with 3D macroporous graphene as cathode and disordered carbon as anode using $\mathrm{Na}^{+}$ion conducting gel polymer as electrolyte in 2015 . The op- 
erating potential was up to $4.2 \mathrm{~V}$, much higher than those of LICs and SICs in liquid electrolytes $[59,78,102]$. After 1200 cycles, the capacitance still remained $85 \%$ of the initial value, demonstrating excellent cycling performance. In addition, the above mentioned SICs with GNS cathode and GNTP anode fabricated by Thangavel et al. [90] also exhibited good performance with the maximum power density of $8000 \mathrm{~W} \mathrm{~kg}^{-1}$ and a low capacitance degradation of $\sim 0.13 \%$ after 1000 cycles.

Additionally, the commercial AC derived from the coal and petroleum coke has been reported as cathode in many previous literatures. Wang and co-workers [52] studied the electrochemical properties of commercial AC consisting of non-uniform nanoparticles with large surface area of $1350 \mathrm{~m}^{2} \mathrm{~g}^{-1}$ (Fig. 6a). The commercial AC showed the operating potential of 3.0-4.3 $\mathrm{V}$ and stable cycling performance with the specific capacity of $43 \mathrm{~mA} \mathrm{~h} \mathrm{~g}^{-1}$ (Fig. 6b and c).

In view of the shortage of the fossil fuels and the in- creasingly serious problems of the environment, biomassderived AC possessing high surface area, high electrical conductivity, low cost, abundant resources, adjustable pore structure and chemical stability have been studied in recent years, such as peanut shells, rice and fish scales $[28,29,31,39,43,44,46,48,50,55,60,62,89,103-108]$. In 2015, Ding et al. [102] prepared both carbon electrode materials from a single precursor of biomass waste peanut shells for the first time (Fig. 6d). During the preparation, the peanut shell was firstly divided into the inner and outer parts through roughly grinding. The outer part was transformed into peanut shell NS carbon (PSNC) containing $35.4 \%$ mesopores $\left(2396 \mathrm{~m}^{2} \mathrm{~g}^{-1}\right)$ as cathode through hydrothermal and subsequently $\mathrm{KOH}$ activation processes (Fig. 6e). The inner part was directly carbonized at $1200^{\circ} \mathrm{C}$ in argon and then activated at $300^{\circ} \mathrm{C}$ in air to obtain peanut shell ordered carbon (PSOC) as anode, along with the interlayer spacing $\left(d_{002}\right)$ of $3.79 \AA$. The fabricated SICs delivered high energy and power densities

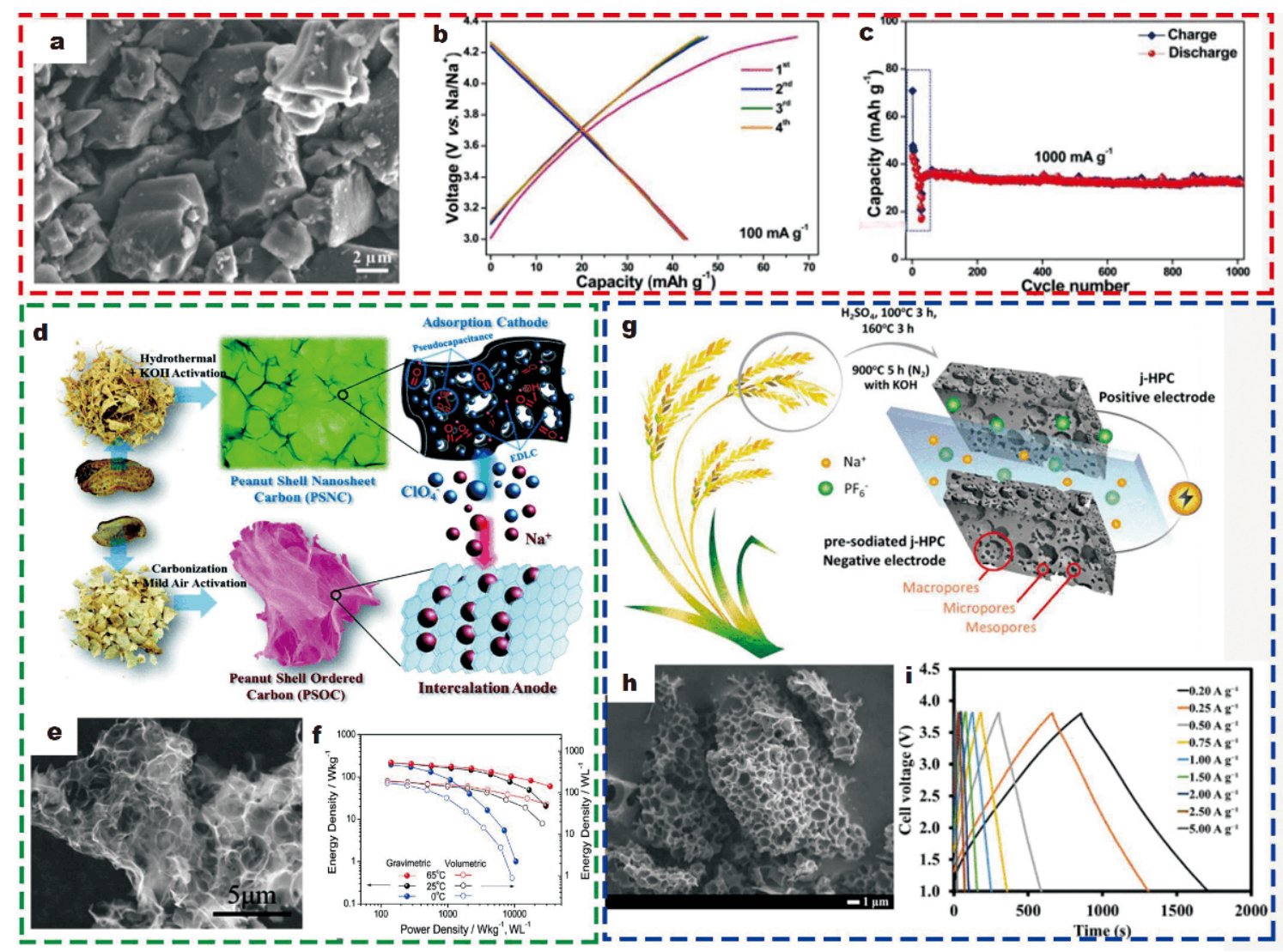

Figure 6 (a-c) Morphological and electrochemical performance of the AC cathode. Reproduced with permission from [52]. Copyright 2018, WileyVCH. (d) The process of cathode/anode materials synthesis and charge storage mechanisms of the SICs. (e) SEM image of PSNC-3-800. (f) Ragone plot of the PSNC-3-800//PSOC-A at different temperatures. Reproduced with permission from [102]. Copyright 2015, Royal Society of Chemistry. (g) Schematic diagram of the SICs with j-HPC. (h) SEM image of j-HPC. (i) GCD curves of the pre-sodiated j-HPC//j-HPC SICs at different current densities. Reproduced with permission from [109]. Copyright 2018, Elsevier. 
of $201 \mathrm{~W} \mathrm{~h} \mathrm{~kg}^{-1}$ and 16,500 $\mathrm{W} \mathrm{kg}^{-1}$ (Fig. 6f), respectively. Encouragingly, when tested at $65^{\circ} \mathrm{C}$, this device exhibited higher power density of $34,000 \mathrm{~W} \mathrm{~kg}^{-1}$ at the energy density of $60 \mathrm{~W} \mathrm{~h} \mathrm{~kg}^{-1}$. In this work, the researchers investigated that the capacitance of the PSNC came from not only the anions adsorption, but also the pseudocapacitance of the defects and oxygen functionalities. In 2018, Phattharasupakun et al. [109] successfully prepared Jasmine rice-derived hierarchical porous carbon (j-HPC) through a solvothermal method followed by activation processes for the first time (Fig. $6 \mathrm{~g}$ and $\mathrm{h}$ ). The as-prepared porous carbon had large specific surface area and average pore diameter of $2377 \mathrm{~m}^{2} \mathrm{~g}^{-1}$ and $2.53 \mathrm{~nm}$, facilitating the anions adsorption on the surface of the materials and Na-ion intercalation. When assembled to SICs based on j-HPC electrodes, the device with the working voltage of $1.0-3.8 \mathrm{~V}$ displayed the maximum energy and power densities of $116.7 \mathrm{~W} \mathrm{~h} \mathrm{~kg}^{-1}$ and $11,121.54 \mathrm{~W} \mathrm{~kg}^{-1}$, respectively, higher than those of previously reported EDHPC//EDHPC and NOFC//PSNC systems (Fig. 6i) [44,108].

These carbon electrodes derived from various biomass materials with low cost, rich reserves, environmentfriendliness and cyclic utilization have the features of porous architecture, large surface area, good electrical conductivity and heteroatom introduction, leading to potential application in sodium-ion storage [27,29$31,39,40,42-44,101-104,108-112]$. As a consequence, we summarized the carbonaceous materials for positive and negative electrodes in SICs in Table 1.

\section{MXenes}

2D MXenes have metallic conductivity and relatively large specific surface area as well as hydrophilia so that they can be used as cathode materials in the SICs. For example, in 2015, Dall'Agnese et al. [36] prepared the $\mathrm{V}_{2} \mathrm{C}$ layered electrode materials from simple etching process and investigated the sodiation mechanism in half cell for the first time. Subsequently, they fabricated a SIC based on $\mathrm{V}_{2} \mathrm{C}$ as cathode and hard carbon (HC) as anode in $1 \mathrm{~mol} \mathrm{~L}^{-1} \mathrm{NaPF}_{6}$ organic electrolyte (Fig. 7a). This SICs with a maximum voltage of $3.5 \mathrm{~V}$ showed prospective applications in ESS (Fig. 7b and c).

In 2017, Zhang et al. [47] prepared $\mathrm{Ti}_{3} \mathrm{C}_{2} \mathrm{~T}_{x}$ NSs with expanded interlayer distance through $\mathrm{HF}$ etching and ultrasonic treatment at room temperature, as shown in Fig. $7 \mathrm{~d}$ and e. For the first time, using $\mathrm{Ti}_{3} \mathrm{C}_{2} \mathrm{~T}_{x}$ as cathode and $\mathrm{MnO}_{2}$ as anode in $\mathrm{Na}_{2} \mathrm{SO}_{4}$ aqueous electrolyte, the researchers assembled the SICs with outstanding rate performance. Even when the current density increased to 250 times of the initial value, the capacity retention still retained 38\% (Fig. 7f). The obtained SIC with a safe

Table 1 Summary of SICs based on both carbonaceous anode and cathode

\begin{tabular}{|c|c|c|c|c|c|}
\hline Anode/cathode & Electrolyte & Voltage (V) & $\begin{array}{c}\operatorname{Max} E\left(\mathrm{~W} \mathrm{~h} \mathrm{~kg}_{1}^{-1}\right) / \max \\
P(\mathrm{~W} \mathrm{~kg})\end{array}$ & Cycle performance & Ref. \\
\hline j-HPC// j-HPC & $1 \mathrm{~mol} \mathrm{~L}^{-1} \mathrm{NaPF}_{6}$ & $1-3.8$ & $116.70 / 11,121.54$ & $90 \%$ over 5000 cycles & [109] \\
\hline CS-800//CS-800-6 & $1 \mathrm{~mol} \mathrm{~L}^{-1} \mathrm{NaClO}_{4}$ & $2-4$ & $52.2 / 3000$ & 85.7 over 2000 cycles & {$[39]$} \\
\hline HPC-550//HPC-800 & $1 \mathrm{~mol} \mathrm{~L}^{-1} \mathrm{NaClO}_{4}$ & $0-4$ & $103.2 / 15,900$ & $81.1 \%$ over 2500 cycles & {$[31]$} \\
\hline 3DCFs//SDAC & $1 \mathrm{~mol} \mathrm{~L}^{-1} \mathrm{NaClO}_{4}$ & $0-4$ & $133.2 / 20,000$ & $86 \%$ over 4000 cycles & {$[104]$} \\
\hline DCDC-K//MCC & $1 \mathrm{~mol} \mathrm{~L}^{-1} \mathrm{NaClO}_{4}$ & $0-4$ & $110.8 / 12,100$ & $85 \%$ over 10000 cycles & {$[29]$} \\
\hline $\mathrm{AC} / / \mathrm{P}-\mathrm{aCNs}$ & $1 \mathrm{~mol} \mathrm{~L}^{-1} \mathrm{NaClO}_{4}$ & $0-2$ & $27.9 / 1379.31$ & $96 \%$ over 100,000 cycles & {$[30]$} \\
\hline $\mathrm{HC} / / \mathrm{BG}$ & $1 \mathrm{~mol} \mathrm{~L}^{-1} \mathrm{NaPF}_{6}$ & $0-4$ & $108 / 6100$ & $97 \%$ over 5000 cycles & {$[110]$} \\
\hline EDHPC//EDHPC & $1 \mathrm{~mol} \mathrm{~L}^{-1} \mathrm{NaClO}_{4}$ & $0-4$ & $84 / 9053$ & $67 \%$ over 5000 cycles & {$[44]$} \\
\hline NOFC//PSNC & $1 \mathrm{~mol} \mathrm{~L}^{-1} \mathrm{NaClO}_{4}$ & $0-4$ & $111 / 14,550$ & $90 \%$ over 5000 cycles & {$[108]$} \\
\hline $\mathrm{DC} / / \mathrm{NC}$ & $1 \mathrm{~mol} \mathrm{~L}^{-1} \mathrm{NaPF}_{6}$ & $0-4.4$ & $157 / 2356$ & $70 \%$ over 1000 cycles & [111] \\
\hline GDY-NS//AC & $1 \mathrm{~mol} \mathrm{~L}^{-1} \mathrm{NaPF}_{6}$ & $2-4$ & $182.3 / 15,000$ & $90 \%$ over 3000 cycles & {$[42]$} \\
\hline HP-CNWs//FM & $1 \mathrm{~mol} \mathrm{~L}^{-1} \mathrm{NaPF}_{6}$ & $0.5-4.2$ & $130.6 / 15,260$ & $85.4 \%$ over 3000 cycles & {$[103]$} \\
\hline $3 \mathrm{DFC} / / 3 \mathrm{DFAC}$ & $1 \mathrm{~mol} \mathrm{~L}^{-1} \mathrm{NaClO}_{4}$ & $0-4$ & $111 / 20,000$ & $75.6 \%$ over 15,000 cycles & {$[112]$} \\
\hline $\mathrm{MCMB} / \mathrm{AC}$ & $1 \mathrm{~mol} \mathrm{~L}^{-1} \mathrm{NaPF}_{6}$ & $1-4$ & $93.5 / 2832$ & $98.3 \%$ over 3000 cycles & {$[40]$} \\
\hline $\mathrm{DC} / / \mathrm{MG}$ & $1 \mathrm{~mol} \mathrm{~L}^{-1} \mathrm{NaClO}_{4}$ & $0-4.2$ & $168 / 2432$ & $85 \%$ over 1200 cycles & {$[101]$} \\
\hline $\mathrm{PSOC} / / \mathrm{PNSC}$ & $1 \mathrm{~mol} \mathrm{~L}^{-1} \mathrm{NaClO}_{4}$ & $1.5-4.2$ & $201.76 / 16,500$ & $72 \%$ over 10,000 cycles & {$[102]$} \\
\hline SCN-A//SCN-A & $1 \mathrm{~mol} \mathrm{~L}^{-1} \mathrm{NaClO}_{4}$ & $0-4$ & $112 / 12,000$ & $85 \%$ over 3000 cycles & {$[43]$} \\
\hline UTH-CN//AC & $1 \mathrm{~mol} \mathrm{~L}^{-1} \mathrm{NaClO}_{4}$ & $0.5-4$ & $110 / 10,000$ & $70 \%$ over 1000 cycles & {$[27]$} \\
\hline
\end{tabular}



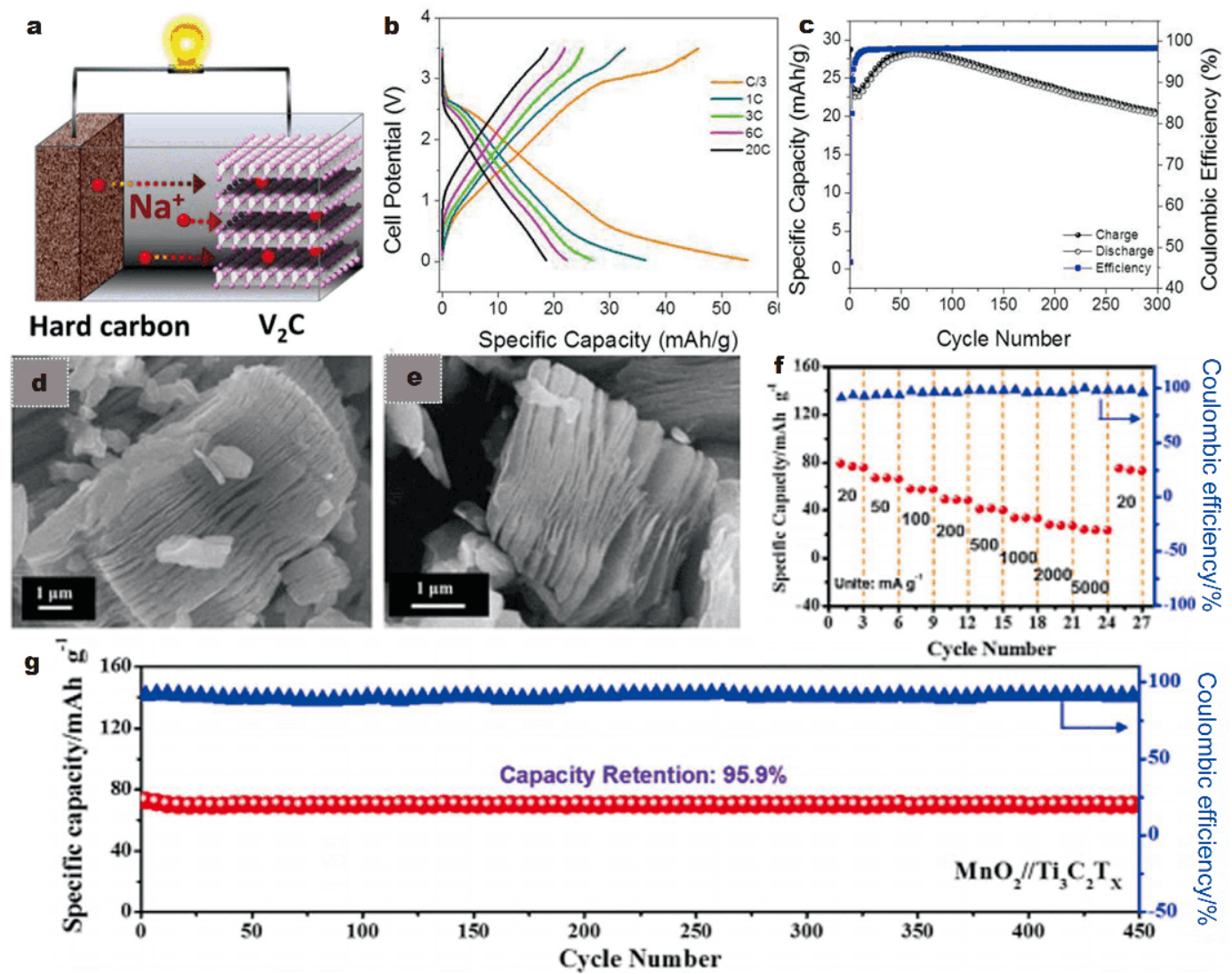

Figure 7 (a) Schematic diagram of the $\mathrm{HC} / / \mathrm{V}_{2} \mathrm{C}$ SICs. (b) GCD curves at different rates. (c) Capacity versus cycle number. Reproduced with permission from [36]. Copyright 2015, American Chemical Society. (d, e) SEM images of $\mathrm{Ti}_{3} \mathrm{C}_{2} \mathrm{~T}_{x}$ before and after ultrasonic treatment. (f, g) Rate performance and cycling properties of the $\mathrm{MnO}_{2} / / \mathrm{Ti}_{3} \mathrm{C}_{2} \mathrm{~T}_{x}$ SICs. Reproduced with permission from [47]. Copyright 2017, Wiley-VCH.

voltage of $0-2.4 \mathrm{~V}$ showed superior cycling stability that $95.9 \%$ of the capacitance retention and over $90 \%$ of the Coulombic efficiency still retained after 450 cycles (Fig. 7g). This aqueous hybrid SICs based on $\mathrm{Ti}_{3} \mathrm{C}_{2} \mathrm{~T}_{x}$ with expanded interlayer distance and efficient ion transport path are low-cost, safe and easily mass-produced in the future.

\section{Prussian blue}

PB and its analogues (PBA) with the advantages of 3D open framework, structure stability, large lattice void, high theoretical capacity (e.g., $170 \mathrm{~mA} \mathrm{~h} \mathrm{~g}^{-1}$ of $\mathrm{Na}_{2} \mathrm{FeFe}-$ $\left.(\mathrm{CN})_{6}\right)$ and the low-cost synthesis are good electrode materials for energy storage [113-115]. The general chemical formula of $\mathrm{PB} / \mathrm{PBA}$ is $\left.\mathrm{A}_{x} \mathrm{P}_{y}\left[\mathrm{R}(\mathrm{CN})_{6}\right)\right]_{z} \cdot n \mathrm{H}_{2} \mathrm{O}$, (A $=\mathrm{K}^{+}$or $\mathrm{Na}^{+}, \mathrm{P} / \mathrm{R}=\mathrm{Fe}^{2+}, \mathrm{Fe}^{3+}, \mathrm{Co}^{2+}, \mathrm{Mn}^{2+}, \mathrm{Ni}^{2+}, \mathrm{Zn}^{2+}$, $\mathrm{Cu}^{2+}$, etc.) The $\mathrm{P}$ and $\mathrm{R}$ cations connected with $-\mathrm{C} \equiv \mathrm{N}$ construct the cubic framework, which includes interstitial A sites [116]. PB with cubic crystal structure contains $\mathrm{Fe}^{2+}$ and $\mathrm{Fe}^{3+}$ ions on the face-centered cubic lattice in turn
(Fig. 8a). When the framework structure of PB allows multiple species to occupy the A, P and R sites, the PBA can be obtained. Recently, PB and PBA as cathode materials in energy storage devices have been widely reported [49,117-119]. For instance, Lu et al. [49] designed the manganous hexacyanoferrate (MnHCF) material with a specific surface area of $218 \mathrm{~m}^{2} \mathrm{~g}^{-1}$ by a co-precipitation method. When the SICs were prepared based on MnHCF as cathode and $\mathrm{Fe}_{3} \mathrm{O}_{4} / \mathrm{rGO}$ as anode in $\mathrm{Na}_{2} \mathrm{SO}_{4}$ aqueous electrolyte, the devices with the operating potential of $0-1.8 \mathrm{~V}$ exhibited high energy and power densities of $43.2 \mathrm{~W} \mathrm{~h} \mathrm{~kg}^{-1}$ and $2183.5 \mathrm{~W} \mathrm{~kg}^{-1}$ as well as $82.2 \%$ of the capacitance retention and $99.5 \%$ of the Coulombic efficiency after 1000 cycles (Fig. 8b and c).

Additionally, in 2015, Lu et al. [117] also obtained Cobased PBA framework using $\mathrm{Co}\left(\mathrm{NO}_{3}\right)_{2}$ and $\mathrm{K}_{3} \mathrm{Fe}(\mathrm{CN})_{6}$ solution by a co-precipitation method. These as-prepared CoHCF with porous network consisted of polydisperse nanoparticles as shown in Fig. 8d. After fabricating SICs by using $\mathrm{CoHCF}$ as cathode and carbon micro-spheres 

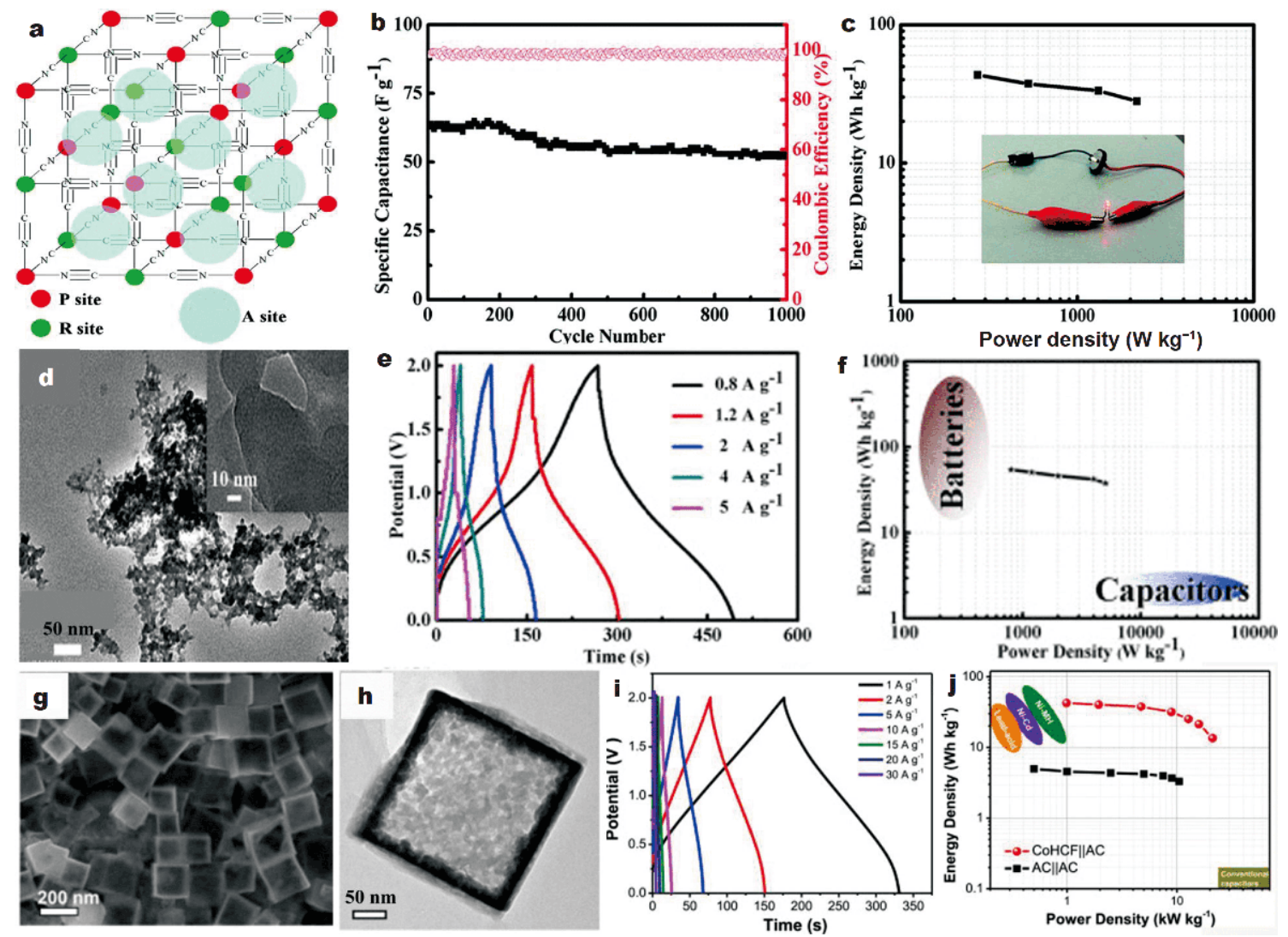

Figure 8 (a) Schematic illustration of the crystal structure of MnHCF. (b) The cycling performance of MnHCF//Fe $\mathrm{O}_{4} / \mathrm{rGO}$ SICs. (c) Ragone plots of the hybrid device. The inset shows that a LED was lighted by two SICs in series. Reproduced with permission from [49]. Copyright 2015, Royal Society of Chemistry. (d) TEM image of CoHCF nanoparticles. The inset is the HRTEM image of CoHCF. (e, f) GCD curves and Ragone plots of the CoHCF//CMS SICs. Reproduced with permission from [117]. Copyright 2015, Elsevier. (g, h) Morphology of the CoHCF submicrocube. (i, j) GCD curves and Ragone plots of the CoHCF//AC hybrid SICs. Reproduced with permission from [119]. Copyright 2017, Elsevier.

(CMS) as anode, a high voltage of $2 \mathrm{~V}$ was obtained in $\mathrm{Na}_{2} \mathrm{SO}_{4}$ aqueous electrolyte (Fig. 8e). Furthermore, the fabricated SICs delivered a high energy density $\left(54.4 \mathrm{~W} \mathrm{~h} \mathrm{~kg}^{-1}\right.$ at $\left.800 \mathrm{~W} \mathrm{~kg} \mathrm{~kg}^{-1}\right)$ and power density $\left(5037 \mathrm{~W} \mathrm{~kg}^{-1}\right.$ at $37.8 \mathrm{~W} \mathrm{~h} \mathrm{~kg}^{-1}$ ) as shown in Fig. 8f. Except for as cathode material, MnHCF can also be used as sacrificial template to produce other hollow structured PBA electrodes due to its high solubility constant $\left(K=1.9 \times 10^{-3}\right)$. In 2017, Wang and co-workers [119] synthesized hollow submicrocube CoHCF with extreme challenge in $\mathrm{Co}\left(\mathrm{NO}_{3}\right)_{2}$ and MnHCF suspension through the cations exchange method (Fig. 8g and h). These prepared hollow submicrocubes with increased surface area $\left(693 \mathrm{~m}^{2} \mathrm{~g}^{-1}\right)$ and more available active sites can relieve structural strain during the electrochemical reactions. The fabricated aqueous SICs of $\mathrm{CoHCF} / / \mathrm{AC}$ showed improved working potential window of $0-2 \mathrm{~V}$ and power density of $21,100 \mathrm{~W} \mathrm{~kg}^{-1}$ (Fig. $8 \mathrm{i}$ and j). Given the features of easy preparation, low costs and capability to be used in aqueous electrolytes, the PB and PBA frameworks with vacant spaces and open channels can significantly facilitate the alkali ions transport and have great promise in future ESS.

Other Na-ion based cathode materials

Sodium metal phosphates $\left(\mathrm{NaMPO}_{4}, \mathrm{M}\right.$ represents $\mathrm{Ni}$, $\mathrm{Mn}, \mathrm{Co}$ and $\mathrm{Fe}$ ) are prospectively used as cathodes with the characteristics of thermal stability attributing to the maricite structure and high working voltage owing to the inductive effect. For instance, in 2014, Senthilkumar et al. [120] synthesized $\mathrm{NaMPO}_{4}(\mathrm{M}=\mathrm{Mn}, \mathrm{Co}, \mathrm{Ni})$ by solution combustion processes, respectively. These three as-prepared compounds exhibited different specific capacitances of $368 \mathrm{~F} \mathrm{~g}^{-1}\left(\mathrm{NaNiPO}_{4}\right), 249 \mathrm{~F} \mathrm{~g}^{-1}\left(\mathrm{NaCoPO}_{4}\right)$ and $163 \mathrm{~F} \mathrm{~g}^{-1}\left(\mathrm{NaMnPO}_{4}\right)$ at the current density of $2 \mathrm{~mA} \mathrm{~cm}^{-2}$ in a three-electrode system of $1 \mathrm{~mol} \mathrm{~L}^{-1} \mathrm{NaOH}$ solution. 
Furthermore, the $\mathrm{AC} / / \mathrm{NaNiPO}_{4}$ SIC device delivered the high energy and power densities of $20 \mathrm{~W} \mathrm{~h} \mathrm{~kg}^{-1}$ and $1358 \mathrm{~W} \mathrm{~kg}^{-1}$ calculated from GCD curves. According to the conductivity sequence of $\mathrm{U}_{\mathrm{Fe}}(3.71 \mathrm{eV})<\mathrm{U}_{\mathrm{Mn}}$ $(3.92 \mathrm{eV})<\mathrm{U}_{\mathrm{Co}}(5.05 \mathrm{eV})<\mathrm{U}_{\mathrm{Ni}}(5.26 \mathrm{eV})$ in the standard Hubbard model (DFT $+\mathrm{U}$ method), the mixed sodium transition metal phosphate $\mathrm{NaMn}_{1 / 3} \mathrm{Co}_{1 / 3} \mathrm{Ni}_{1 / 3} \mathrm{PO}_{4}$ has attracted much attention because of its narrowed band gap and enhanced conductivity. In 2015, Sundaram and co-workers [121] prepared the $\mathrm{NaMn}_{1 / 3} \mathrm{Co}_{1 / 3} \mathrm{Ni}_{1 / 3} \mathrm{PO}_{4}$ maricite structure via a sol-gel process. With $\mathrm{NaMn}_{1 / 3^{-}}$ $\mathrm{Co}_{1 / 3} \mathrm{Ni}_{1 / 3} \mathrm{PO}_{4}$ as cathode and carbon as anode, the fabricated SIC device achieved an energy density of $50 \mathrm{~W} \mathrm{~h} \mathrm{~kg}^{-1}$ at the power density of $180 \mathrm{~W} \mathrm{~kg}^{-1}$ in $1 \mathrm{~mol} \mathrm{~L}^{-1} \mathrm{NaPF}_{6}$ non-aqueous electrolyte.

$\mathrm{Na}_{3} \mathrm{~V}_{2}\left(\mathrm{PO}_{4}\right)_{3}$ (NVP) can be used as both anode and cathode electrodes for SIC, in which one Na ion can easily insert into or two Na ions extract from the NVP host with two distinctive plateaus of 1.6 and $3.4 \mathrm{~V}$, respectively. For example, using porous $\mathrm{C} / \mathrm{V}_{2} \mathrm{O}_{5}$ composite as precursor, Jian et al. [86] prepared NVP electrode material with improved electrical conductivity through an ambient hydrolysis deposition method. The fabricated symmetric $\mathrm{Na}$-ion pseudocapacitor in $\mathrm{NaPF}_{6}$ organic electrolyte exhibited the features of high reversibility, high-rate as well as low cost and bridged the performance gap between the batteries and SCs.

In summary, Na-ion based transition metal compounds with 3D porous framework, large-sized tunnels, improved conductivity and cost-effective characteristics can be used as electrodes in sodium ion storage systems. As mentioned above, the chosen $\mathrm{Na}_{0.44} \mathrm{MnO}_{2}$ and $\mathrm{Na}_{0.21} \mathrm{MnO}_{2}$ with excellent cycling stability and good rate performance have been reported as cathodes in the $\mathrm{Ti}_{3} \mathrm{C}_{2} \mathrm{~T}_{x} / \mathrm{CNT} / /$ $\mathrm{Na}_{0.44} \mathrm{MnO}_{2}$ and $\mathrm{rGO} / / \mathrm{Na}_{0.21} \mathrm{MnO}_{2}$ SICs, respectively $[41,80]$. Moreover, the alluaudite-type $\mathrm{Na}_{2} \mathrm{Fe}_{2}\left(\mathrm{SO}_{4}\right)_{3}$ with a theoretical capacity of $120 \mathrm{~mA} \mathrm{~h} \mathrm{~g}^{-1}$ and a high redox voltage of $3.8 \mathrm{~V}$ has been used as cathode to fabricate hybrid sodium ion pseudocapacitor by Zhu et al. [77]. According to this work, it is suggested that other alluaudite-type compounds of $\mathrm{Na}_{2-x} \mathrm{M}_{2}\left(\mathrm{SO}_{4}\right)_{3}(\mathrm{M}=\mathrm{Ti}$, Co, $\mathrm{Mn}, \mathrm{Mg}, \mathrm{V}, \mathrm{Ni}$ or $\mathrm{VO}$ ) are also worthy of being explored as electrode materials for sodium ion storage in the future.

\section{ELECTROLYTES}

The electrolytes used in the SIC devices commonly consist of organic electrolytes, aqueous electrolytes and ionic liquid electrolytes. Among these electrolytes, the ionic conductivities of aqueous electrolytes are the highest (up to $1 \mathrm{~S} \mathrm{~cm}^{-1}$ ). The aqueous electrolytes own the low cost and safe features. However, the electrochemical stable window was limited to $1.23 \mathrm{~V}$ due to the decomposition of water [122]. Compared with aqueous systems, organic electrolytes possess wider potential window $(\sim 4 \mathrm{~V})$ because of their higher decomposition voltage, whereas they are not safe with the disadvantages of toxicity, volatility and low flash point $\left(\sim 80^{\circ} \mathrm{C}\right)$ for energy storage devices [122]. Additionally, ionic liquid electrolytes with nonflammability, low-volatility and high ignition temperature $\left(>300^{\circ} \mathrm{C}\right)$ other than low conductivity and high viscosity can provide large potential windows and stable solid electrolyte interphase (SEI) film with the absence of dendrites when applied in electrochemical storage systems [123].

Generally, the aqueous systems including acid-based, alkali-based and neutral electrolytes are often involved in recent years $[47,68,84,117,124-126]$. For example, the reported $\mathrm{Na}_{4} \mathrm{Mn}_{9} \mathrm{O}_{18} / / \mathrm{AC}$ hybrid capacitor system [127] in $1 \mathrm{~mol} \mathrm{~L}^{-1} \mathrm{NaCl}$ aqueous solution displayed stable cycling performance (Fig. 9a and b). In $2 \mathrm{~mol} \mathrm{~L}^{-1} \mathrm{Na}_{2} \mathrm{SO}_{4}$ aqueous electrolyte, the fabricated $\mathrm{Na}_{0.21} \mathrm{MnO}_{2} / / \mathrm{rGO}$ SICs [41] displayed an operating voltage of $2.7 \mathrm{~V}$, much higher than other aqueous SICs (Fig. 9c) [47,68,84,127]. It is concluded that the strong bonding of $\mathrm{Mn}^{3+}$ with adsorbed $\mathrm{OH}^{-}$ions in these SICs can lead to higher overpotential of Mn-based compounds towards water oxidation. In addition, the authors compared the electrochemical performances of the $\mathrm{NaMPO}_{4}(\mathrm{M}=\mathrm{Mn}, \mathrm{Co}, \mathrm{Ni})$ in various Na-based aqueous electrolytes (Fig. 9d). The specific capacitances of $\mathrm{NaMPO}_{4}$ in $1 \mathrm{~mol} \mathrm{~L}^{-1} \mathrm{NaOH}$ aqueous solution were much higher than that in $\mathrm{Na}_{2} \mathrm{SO}_{4}, \mathrm{NaCl}$ and $\mathrm{NaNO}_{3}$ solutions, which was derived from the smaller ionic solvation radius of $\mathrm{OH}^{-}(3.00 \AA)$ than those of $\mathrm{NO}_{3}{ }^{-}$ $(3.35 \AA), \mathrm{Cl}^{-}(3.32 \AA)$ and $\mathrm{SO}_{4}{ }^{2-}(3.79 \AA)$. Furthermore, the pseudocapacitance reactions in alkali condition also contributed to improve the electrochemical performance [120]. Significantly, the "water-in-salt" electrolyte with high salt concentration has been investigated in recent years. Compared with the common aqueous solution, the high-concentration electrolyte can provide wider as well as more stable voltage window and more easily form the passivation layer on the surface of electrode materials, leading to high electrochemical performance. For instance, in $17 \mathrm{~mol} \mathrm{~L}^{-1} \mathrm{NaClO}_{4}$ aqueous electrolyte with the maximum window of $2.75 \mathrm{~V}$, Zhang et al. [124] successfully assembled the $\mathrm{PI} /$ /porous carbon microspheres SICs. The enhanced operating voltage of $2 \mathrm{~V}$ guaranteed that the SICs delivered a high energy density $\left(65 \mathrm{~W} \mathrm{~h} \mathrm{~kg}^{-1}\right)$ and a high power density $\left(20,000 \mathrm{~W} \mathrm{~kg}^{-1}\right)$. 

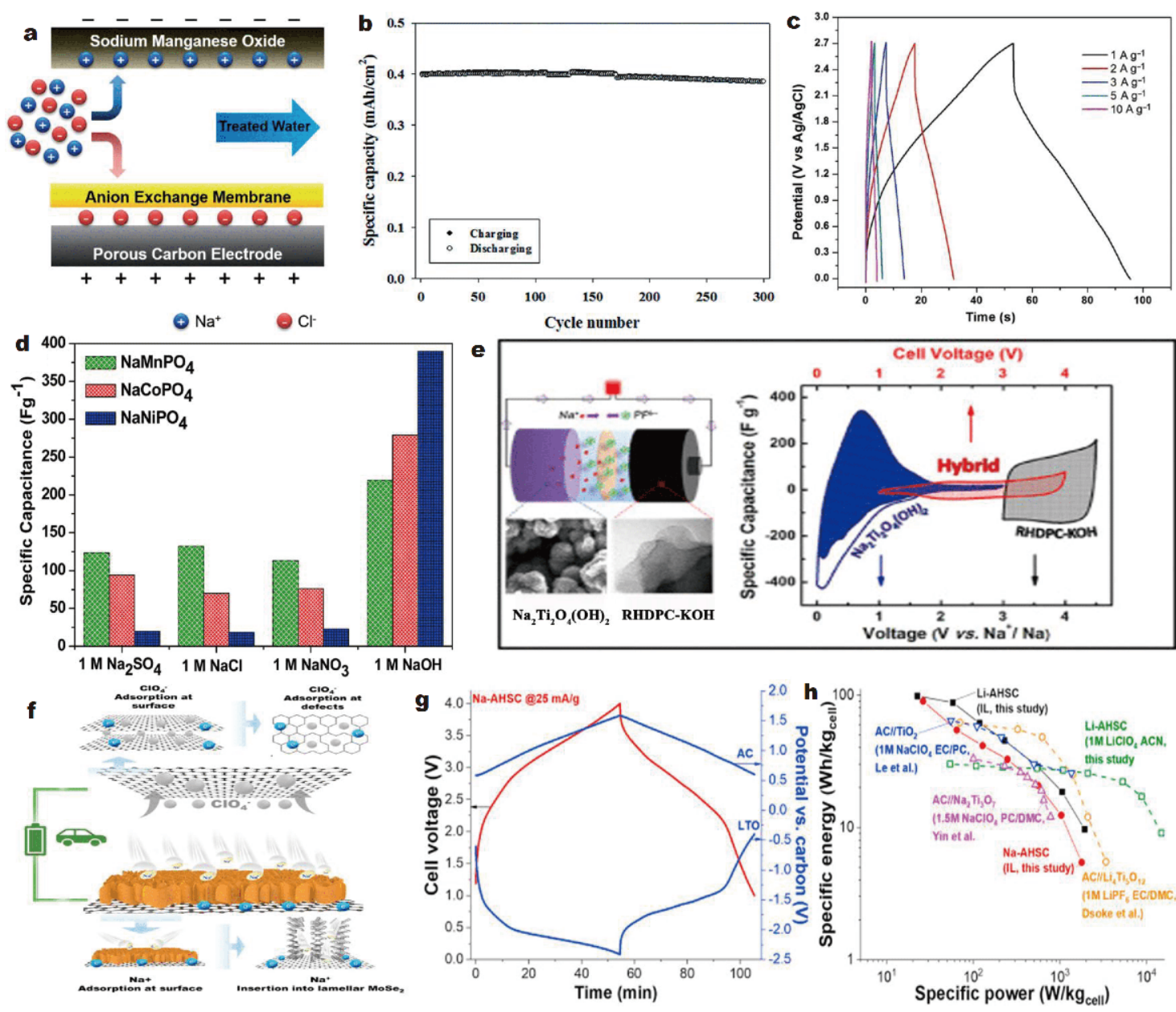

Figure 9 (a) Schematic of desalination by hybrid capacitive deionization (HCDI). (b) Specific capacity versus cycle number. Reproduced with permission from [127]. Copyright 2014, Royal Society of Chemistry. (c) GCD profiles of the $\mathrm{Na}_{4} \mathrm{Mn}_{9} \mathrm{O}_{18} / / \mathrm{AC}$ device in $2 \mathrm{~mol} \mathrm{~L}^{-1} \mathrm{Na}_{2} \mathrm{SO}_{4}$ aqueous electrolyte. Reproduced with permission from [41]. Copyright 2017, Wiley-VCH. (d) Capacitance of $\mathrm{NaMPO}_{4}(\mathrm{M}=\mathrm{Ni}, \mathrm{Co}, \mathrm{Fe}$ and $\mathrm{Mn}$ ) in different aqueous electrolytes. Reproduced with permission from [120]. Copyright 2014, Royal Society of Chemistry. (e) CV curves of the two half cells and hybrid $\mathrm{Na}_{2} \mathrm{Ti}_{2} \mathrm{O}_{4}(\mathrm{OH})_{2} / /$ RHDPC-KOH SIC in $1 \mathrm{~mol} \mathrm{~L}^{-1} \mathrm{NaPF}_{6}$ organic electrolyte. Reproduced with permission from [106]. Copyright 2017, Elsevier. (f) Schematic illustration of the charge-storage mechanisms for the $\mathrm{MoSe}_{2} / \mathrm{G} / / \mathrm{AC}$ in $1 \mathrm{~mol} \mathrm{~L}^{-1} \mathrm{NaClO}_{4}$ organic electrolyte. Reproduced with permission from [72]. Copyright 2018, Elsevier. (g) Voltage profiles of the SICs at $25 \mathrm{~mA} \mathrm{~g}^{-1}$. (h) Ragone plot of the $\mathrm{Li}_{4} \mathrm{Ti}_{5} \mathrm{O}_{12} / / \mathrm{AC}$ SICs with a comparison to the reports. Reproduced with permission from [100]. Copyright 2018, Elsevier.

Presently, the organic electrolytes composed of $\mathrm{NaClO}_{4}$ or $\mathrm{NaPF}_{6}$ in cyclic carbonate esters (PC and $\mathrm{EC}$ ) and linear carbonates (EMC, DMC and DEC) with a certain ratio have been widely used in SICs $[28-30,42,48,52,101$, $108,110,112]$. Additionally, 5\% fluoroethylene carbonate (FEC) as additive was frequently added into the above organic systems, which can contribute to improving passivation and suppressing the side reactions (Fig. 9e and f) $[72,106]$. In these systems, $\mathrm{Na}^{+}$cations were stored through insertion process and $\mathrm{ClO}_{4}^{-} / \mathrm{PF}_{6}^{-}$anions were adsorbed on the surface of the cathode, simultaneously.

The ionic liquid electrolytes with various advantages are highlighted in the research of SICs in spite of their high viscosity and low conductivity $[100,128,129]$. When used at high temperature below the melting point of sodium $\left(98^{\circ} \mathrm{C}\right)$, their disadvantages can be effectively alleviated. Fig. 9g shows the GCD curves of the SICs [100] based on $\mathrm{Li}_{4} \mathrm{Ti}_{5} \mathrm{O}_{12}$ as anode and $\mathrm{AC}$ as cathode with $0.8 \mathrm{~mol} \mathrm{~L}^{-1}$ sodium bis(fluorosulfonyl)imide (Na-TFSI) in 1-methyl-1-propylpyrrolidinium bis(trifluoromethylsulfonyl)imide (PMPyrr-TFSI) electrolyte. The SIC devices operated from 1.0 to $4.0 \mathrm{~V}$ at the current density of $25 \mathrm{~mA} \mathrm{~g}^{-1}$ and achieved $69 \%$ capacitance retention after 1500 cycles. However, the cycling stability is barely sa- 
tisfactory because of the large ionic radius of $\mathrm{Na}^{+}$. The calculated specific energy and power densities were $90 \mathrm{~W} \mathrm{~h} \mathrm{~kg}^{-1}$ and $1780 \mathrm{~W} \mathrm{~kg}^{-1}$, superior than other organic electrolyte systems of $\mathrm{AC} / / \mathrm{Na}_{2} \mathrm{Ti}_{3} \mathrm{O}_{7}\left(1.5 \mathrm{~mol} \mathrm{~L}^{-1}\right.$ $\left.\mathrm{NaClO}_{4} \quad \mathrm{PC} / \mathrm{DMC}\right)$ and $\mathrm{AC} / / \mathrm{TiO}_{2}\left(\begin{array}{lll}1 \mathrm{~mol} \mathrm{~L}^{-1} & \mathrm{NaClO}_{4}\end{array}\right.$ EC/PC) (Fig. 9h) [54,59].

\section{PRESENTATION OF SICs AND THEIR POTENTIAL APPLICATIONS}

Generally, there are three types of SICs: coin, pouch and flexible packaging. The liquid and quasi-solid-state electrolytes both can be used in the flexible packaging cells. Specially, the common quasi-solid-state electrolyte in SICs was based on poly(vinylidenefluoride-hexafluoropropylene) (P(VDF-HFP)) [60,62,101]. Briefly, the $\mathrm{P}$ (VDF-HFP) was firstly dissolved in the mixture of dimethyl formamide (DMF) and distilled water with a certain ratio. The solution was cast onto a clean glass plate and then immersed into hot water to obtain a homogeneous white membrane. After being dried in the vacuum, the white membrane was finally soaked in the organic electrolyte to get the quasi-solid-state electrolyte.
Additionally, other cellulose-based quasi-solid-state electrolytes can be also used in SICs [130-132]. In the preparation, hydroxyethyl cellulose (HEC), polyethylene oxide (PEO) and sodium perchlorate $\left(\mathrm{NaClO}_{4}\right)$ were first dissolved in deionized water, followed by adding silicon dioxide $\left(\mathrm{SiO}_{2}\right)$. Then the solution was transferred into a Teflon petri dish and dried to form a cellulose-based membrane (HEC-PEO).

After the successful fabrication of SICs based on various electrode materials and electrolytes with high electrochemical performance, the practical use should be considered. However, the application field of the SICs was less reported except for powering the LED lamps and fans $[40,52,58,62]$. As shown in Fig. 10a and b, the LED bulb and fan were powered by a GDY-NS//AC coin SIC and a graphitic mesocarbon microbead (MCMB)//AC SIC with hard aluminum shell, respectively $[40,42]$. Fig. 10c presents a table lamp lighted by a flexible all-solid-state $\mathrm{Na}_{2} \mathrm{Ti}_{3} \mathrm{O}_{7} / /$ PSC SIC [62]. Additionally, the SICs with high energy and power densities can be hopefully applied in EVs and urban rail transports. As an example, regenerative braking energy of urban rail transport can be
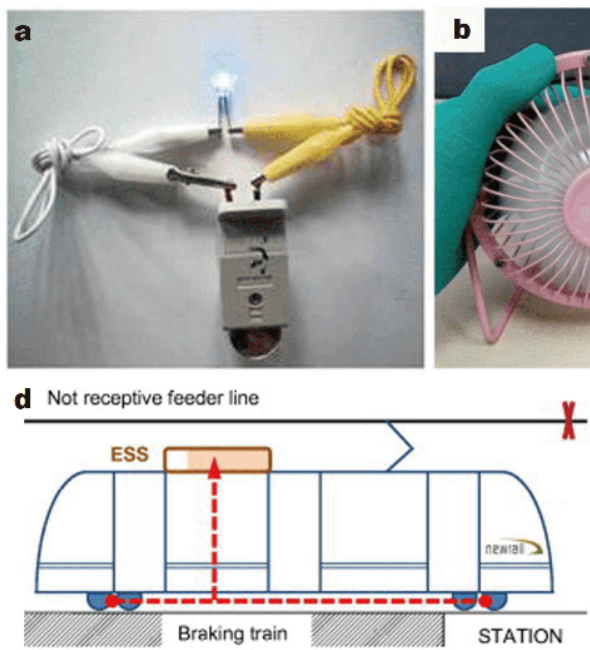

Charging mode

e Feeder line

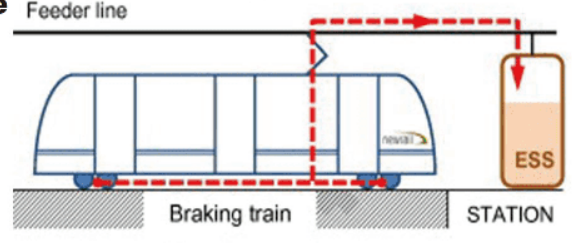

Charging mode
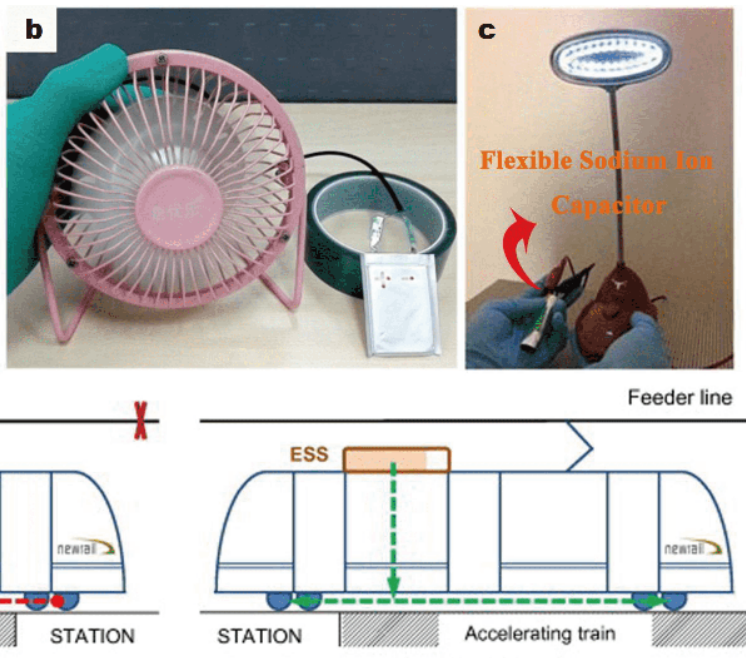

Discharging mode

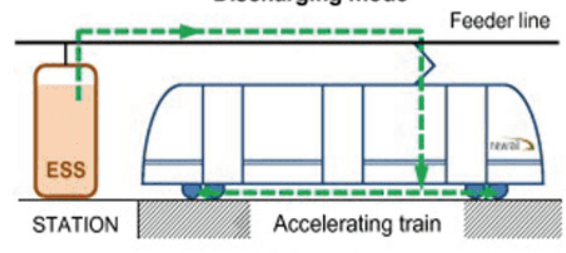

Discharging mode

Figure $10(a-c)$ The LED bulb, fan and table lamp were powered by coin, pouch and flexible all-solid-state SICs (from left to right). Reproduced with permission from [42], [40] and [62]. Copyright 2017, American Chemical Society; Copyright 2015, Elsevier and Copyright 2016, American Chemical Society, respectively. (d, e) Schematic diagram of ESSs operation in urban rail on-board and way-side. Reproduced with permission from [133]. Copyright 2013, Elsevier. 
efficiently stored in the ESS, which can be designed onboard or way-side [133]. During the braking process, the energy was collected and stored in the on-board ESS, which can be employed to charge the vehicle itself when it was accelerating as shown in Fig. 10d. Similarly, the regenerative braking energy obtained from one vehicle can be conveyed to the way-side ESS momentarily, and then used on any vehicle that needs to accelerate as shown in Fig. 10e. This application can decrease the power peak value demanded in the acceleration and save energy cost, significantly.

\section{CONCLUSIONS AND OUTLOOK}

In this review, the latest development of SICs has been systematically summarized. We first classify the frequent electrode materials for the anode and cathode and then sum up the approaches to improve the electrochemical performance from the aspects of lattice distance, heteroatom doping, specific surface area and electronic conductivity. Notably, heteroatom modification can enhance the wettability of the voids, which is beneficial to the contact between the electrolyte and the electrode and delivering pseudocapacitive behaviors. At the same time, some micro/nanostructured materials can reduce the distance of Na-ion transport, effectively improving the reaction kinetics. Moreover, incorporating carbon materials into the electrodes contributes to boosting the electronic conductivity. Meanwhile, the respective working conditions of the electrolytes as well as the presentation and potential application of the SICs in urban rail transport are also introduced in detail.

Although some progress has been made in SICs, there are still some shortcomings to be solved. For example, one major challenge is how to overcome the sluggish diffusion behavior of Na-ion to balance the kinetics with cathode adsorption/desorption. Consequently, further research emphasis should be paid attention to as follows:

(i) Although there are many anode materials used in SICs, the electrochemical performance is far behind the demands of practical application. Developing new hosts with large lattice space available for $\mathrm{Na}^{+}$ions insertion as well as 3D nanostructured arrays germinated on the current collectors without binders or additives are extremely urgent.

(ii) Besides, the SICs designed with both carbon-based anode and cathode prospectively supply good electrochemical properties due to good electronic conductivity, mesoporous structures and high specific surface area. Moreover, developing the biomass-derived carbon electrodes can not only decrease the material costs but also promote waste recycling.

(iii) The high energy density is mainly derived from high voltage, which is dependent on the working potential of the electrolyte. It is worth noting that ionic liquid electrolytes possess high voltage and relatively safe features. Different conjugation of anions and cations may improve the ionic conductivity and potential window of the ionic liquid electrolytes. Meanwhile, the SICs can be well used in a wide range of temperature. Additionally, the "water-in-salt" electrolytes that can get rid of the limitation of water electrolysis should be optimized to achieve higher voltage.

(iv) The flexible SICs will be a promising filed in the future, which can be used in our daily life. However, the corresponding reports are few according to the current situation. As a consequence, more attention should be paid to the all-solid-state gel sodium-containing electrolyte and flexible substrates.

(v) At the moment, the application of the SICs are primarily concentrated on lighting LED lamps. Whereas, the integration of the SICs with other sensors, detectors and energy harvester is important for achieving more practical values. In this respect, taking more effort on the integration can efficiently stimulate the development of the SICs.

(vi) Despite the rapid development of materials science, the theory calculations should be enhanced in the field of SICs, which can contribute to establishing models and providing more convincing evidence for the experimental results, simultaneously.

Received 4 September 2019; accepted 19 September 2019; published online 4 November 2019

1 Lu X, Yu M, Wang G, et al. Flexible solid-state supercapacitors: design, fabrication and applications. Energy Environ Sci, 2014, 7: 2160-2181

2 Lim E, Kim H, Jo C, et al. Advanced hybrid supercapacitor based on a mesoporous niobium pentoxide/carbon as high-performance anode. ACS Nano, 2014, 8: 8968-8978

3 Simon P, Gogotsi Y, Dunn B. Where do batteries end and supercapacitors begin? Science, 2014, 343: 1210-1211

4 Zuo W, Li R, Zhou C, et al. Battery-supercapacitor hybrid devices: recent progress and future prospects. Adv Sci, 2017, 4: 1600539

5 Kim H, Cho MY, Kim MH, et al. A novel high-energy hybrid supercapacitor with an anatase $\mathrm{TiO}_{2}$-reduced graphene oxide anode and an activated carbon cathode. Adv Energy Mater, 2013, 3: $1500-1506$

6 Won JH, Jeong HM, Kang JK. Synthesis of nitrogen-rich nanotubes with internal compartments having open mesoporous channels and utilization to hybrid full-cell capacitors enabling high energy and power densities over robust cycle life. Adv En- 
ergy Mater, 2017, 7: 1601355

7 Zhang F, Zhang T, Yang X, et al. A high-performance supercapacitor-battery hybrid energy storage device based on graphene-enhanced electrode materials with ultrahigh energy density. Energy Environ Sci, 2013, 6: 1623-1632

8 Wang F, Liu Z, Wang X, et al. A conductive polymer coated $\mathrm{MoO}_{3}$ anode enables an Al-ion capacitor with high performance. J Mater Chem A, 2016, 4: 5115-5123

9 Larcher D, Tarascon JM. Towards greener and more sustainable batteries for electrical energy storage. Nat Chem, 2015, 7: 19-29

10 Yun YS, Cho SY, Shim J, et al. Microporous carbon nanoplates from regenerated silk proteins for supercapacitors. Adv Mater, 2013, 25: 1993-1998

11 Lee SW, Gallant BM, Byon HR, et al. Nanostructured carbonbased electrodes: bridging the gap between thin-film lithium-ion batteries and electrochemical capacitors. Energy Environ Sci, 2011, 4: 1972

12 Ma Y, Chang H, Zhang M, et al. Graphene-based materials for lithium-ion hybrid supercapacitors. Adv Mater, 2015, 27: 52965308

13 Li B, Dai F, Xiao Q, et al. Activated carbon from biomass transfer for high-energy density lithium-ion supercapacitors. Adv Energy Mater, 2016, 6: 1600802

14 Yang M, Zhong Y, Ren J, et al. Fabrication of high-power Li-ion hybrid supercapacitors by enhancing the exterior surface charge storage. Adv Energy Mater, 2015, 5: 1500550

15 Aravindan V, Gnanaraj J, Lee YS, et al. Insertion-type electrodes for nonaqueous Li-ion capacitors. Chem Rev, 2014, 114: 1161911635

$16 \mathrm{Gu} \mathrm{H}$, Zhu YE, Yang J, et al. Nanomaterials and technologies for lithium-ion hybrid supercapacitors. ChemNanoMat, 2016, 2: 578-587

17 Yu X, Zhan C, Lv R, et al. Ultrahigh-rate and high-density lithium-ion capacitors through hybriding nitrogen-enriched hierarchical porous carbon cathode with prelithiated microcrystalline graphite anode. Nano Energy, 2015, 15: 43-53

18 Puthusseri D, Aravindan V, Anothumakkool B, et al. From waste paper basket to solid state and Li-HEC ultracapacitor electrodes: A value added journey for shredded office paper. Small, 2014, 10: 4395-4402

19 Wang F, Wang C, Zhao Y, et al. A quasi-solid-state Li-ion capacitor based on porous $\mathrm{TiO}_{2}$ hollow microspheres wrapped with graphene nanosheets. Small, 2016, 12: 6207-6213

20 Slater MD, Kim D, Lee E, et al. Sodium-ion batteries. Adv Funct Mater, 2013, 23: 947-958

21 Ding J, Hu W, Paek E, et al. Review of hybrid ion capacitors: from aqueous to lithium to sodium. Chem Rev, 2018, 118: 6457-6498

22 Wang $\mathrm{H}$, Zhu C, Chao D, et al. Nonaqueous hybrid lithium-ion and sodium-ion capacitors. Adv Mater, 2017, 29: 1702093

23 Aravindan V, Ulaganathan M, Madhavi S. Research progress in Na-ion capacitors. J Mater Chem A, 2016, 4: 7538-7548

24 Li F, Zhou Z. Micro/nanostructured materials for sodium ion batteries and capacitors. Small, 2018, 14: 1702961

25 Zhu C, Yang P, Chao D, et al. Heterogeneous nanostructures for sodium ion batteries and supercapacitors. ChemNanoMat, 2015, 1: $458-476$

26 Luo J, Fang C, Jin C, et al. Tunable pseudocapacitance storage of MXene by cation pillaring for high performance sodium-ion capacitors. J Mater Chem A, 2018, 6: 7794-7806

27 Yun YS, Cho SY, Kim H, et al. Ultra-thin hollow carbon nano- spheres for pseudocapacitive sodium-ion storage. ChemElectroChem, 2015, 2: 359-365

28 Kim NR, Yun YS, Song MY, et al. Citrus-peel-derived, nanoporous carbon nanosheets containing redox-active heteroatoms for sodium-ion storage. ACS Appl Mater Interfaces, 2016, 8: 3175-3181

29 Dong G, Wang H, Liu W, et al. Nitrate salt assisted fabrication of highly $\mathrm{N}$-doped carbons for high-performance sodium ion capacitors. ACS Appl Energy Mater, 2018, acsaem.8b01166

30 Park SK, Kwon SH, Lee SG, et al. $10^{5}$ Cyclable pseudocapacitive Na-ion storage of hierarchically structured phosphorus-incorporating nanoporous carbons in organic electrolytes. ACS Energy Lett, 2018, 3: 724-732

31 Liu M, Niu J, Zhang Z, et al. Porous carbons with tailored heteroatom doping and well-defined porosity as high-performance electrodes for robust Na-ion capacitors. J Power Sources, 2019, 414: 68-75

32 Zou K, Cai P, Liu C, et al. A kinetically well-matched full-carbon sodium-ion capacitor. J Mater Chem A, 2019, 7: 13540-13549

33 Zou G, Hou H, Foster CW, et al. Advanced hierarchical vesicular carbon Co-doped with S, P, N for high-rate sodium storage. Adv Sci, 2018, 5: 1800241

34 Hou H, Banks CE, Jing M, et al. Carbon quantum dots and their derivative 3D porous carbon frameworks for sodium-ion batteries with ultralong cycle life. Adv Mater, 2015, 27: 7861-7866

35 Kuratani K, Yao M, Senoh $\mathrm{H}$, et al. Na-ion capacitor using sodium pre-doped hard carbon and activated carbon. Electrochim Acta, 2012, 76: 320-325

36 Dall'Agnese Y, Taberna PL, Gogotsi Y, et al. Two-dimensional vanadium carbide (MXene) as positive electrode for sodium-ion capacitors. J Phys Chem Lett, 2015, 6: 2305-2309

37 Li Z, Bommier C, Chong ZS, et al. Mechanism of Na-ion storage in hard carbon anodes revealed by heteroatom doping. Adv Energy Mater, 2017, 7: 1602894

38 Qiu S, Xiao L, Sushko ML, et al. Manipulating adsorption-insertion mechanisms in nanostructured carbon materials for highefficiency sodium ion storage. Adv Energy Mater, 2017, 7: 1700403

39 Wang S, Wang R, Zhang $\mathrm{Y}$, et al. Scalable and sustainable synthesis of carbon microspheres via a purification-free strategy for sodium-ion capacitors. J Power Sources, 2018, 379: 33-40

40 Han P, Han X, Yao J, et al. High energy density sodium-ion capacitors through co-intercalation mechanism in diglyme-based electrolyte system. J Power Sources, 2015, 297: 457-463

41 Karikalan N, Karuppiah C, Chen SM, et al. Three-dimensional fibrous network of $\mathrm{Na}_{0.21} \mathrm{MnO}_{2}$ for aqueous sodium-ion hybrid supercapacitors. Chem Eur J, 2017, 23: 2379-2386

42 Wang K, Wang N, He J, et al. Preparation of 3D architecture graphdiyne nanosheets for high-performance sodium-ion batteries and capacitors. ACS Appl Mater Interfaces, 2017, 9: 4060440613

43 Wang H, Mitlin D, Ding J, et al. Excellent energy-power characteristics from a hybrid sodium ion capacitor based on identical carbon nanosheets in both electrodes. J Mater Chem A, 2016, 4: 5149-5158

44 Liu X, Wang H, Cui Y, et al. High-energy sodium-ion capacitor assembled by hierarchical porous carbon electrodes derived from enteromorpha. J Mater Sci, 2018, 53: 6763-6773

45 Chen Z, Augustyn V, Jia X, et al. High-performance sodium-ion pseudocapacitors based on hierarchically porous nanowire com- 
posites. ACS Nano, 2012, 6: 4319-4327

46 Kiruthiga R, Nithya C, Karvembu R, et al. Reduced graphene oxide embedded $\mathrm{V}_{2} \mathrm{O}_{5}$ nanorods and porous honey carbon as high performance electrodes for hybrid sodium-ion supercapacitors. Electrochim Acta, 2017, 256: 221-231

47 Zhu K, Zhang H, Ye K, et al. Two-dimensional titanium carbide MXene as a capacitor-type electrode for rechargeable aqueous $\mathrm{Li}$ ion and Na-ion capacitor batteries. ChemElectroChem, 2017, 4: 3018-3025

48 Ramakrishnan K, Nithya C, Karvembu R. High-performance sodium ion capacitor based on $\mathrm{MoO}_{2} @ \mathrm{rGO}$ nanocomposite and goat hair derived carbon electrodes. ACS Appl Energy Mater, 2018, 1: 841-850

$49 \mathrm{Lu} \mathrm{K}, \mathrm{Li} \mathrm{D}$, Gao X, et al. An advanced aqueous sodium-ion supercapacitor with a manganous hexacyanoferrate cathode and a $\mathrm{Fe}_{3} \mathrm{O}_{4} / \mathrm{rGO}$ anode. J Mater Chem A, 2015, 3: 16013-16019

50 Li H, Zhu Y, Dong S, et al. Self-assembled $\mathrm{Nb}_{2} \mathrm{O}_{5}$ nanosheets for high energy-high power sodium ion capacitors. Chem Mater, 2016, 28: 5753-5760

51 Lim E, Jo C, Kim MS, et al. High-performance sodium-ion hybrid supercapacitor based on $\mathrm{Nb}_{2} \mathrm{O}_{5} @$ carbon core-shell nanoparticles and reduced graphene oxide nanocomposites. Adv Funct Mater, 2016, 26: 3711-3719

52 Wang $\mathrm{X}$, Li Q, Zhang $\mathrm{L}$, et al. Caging $\mathrm{Nb}_{2} \mathrm{O}_{5}$ nanowires in PECVD-derived graphene capsules toward bendable sodium-ion hybrid supercapacitors. Adv Mater, 2018, 30: 1800963

53 Wu Y, Fan X, Gaddam RR, et al. Mesoporous niobium pentoxide/ carbon composite electrodes for sodium-ion capacitors. J Power Sources, 2018, 408: 82-90

54 Le Z, Liu F, Nie P, et al. Pseudocapacitive sodium storage in mesoporous single-crystal-like $\mathrm{TiO}_{2}$-graphene nanocomposite enables high-performance sodium-ion capacitors. ACS Nano, 2017, 11: 2952-2960

55 Zhu YE, Yang L, Sheng J, et al. Fast sodium storage in $\mathrm{TiO}_{2} @$ CNT@C nanorods for high-performance Na-ion capacitors. Adv Energy Mater, 2017, 7: 1701222

56 Babu B, Ullattil SG, Prasannachandran $\mathrm{R}$, et al. $\mathrm{Ti}^{3+}$ induced brown $\mathrm{TiO}_{2}$ nanotubes for high performance sodium-ion hybrid capacitors. ACS Sustain Chem Eng, 2018, 6: 5401-5412

57 Gao L, Chen S, Zhang L, et al. High performance sodium ion hybrid supercapacitors based on $\mathrm{Na}_{2} \mathrm{Ti}_{3} \mathrm{O}_{7}$ nanosheet arrays. $\mathrm{J}$ Alloys Compd, 2018, 766: 284-290

58 Dong S, Shen L, Li H, et al. Flexible sodium-ion pseudocapacitors based on $3 \mathrm{D} \mathrm{Na} \mathrm{Ni}_{3} \mathrm{O}_{7}$ nanosheet arrays/carbon textiles anodes. Adv Funct Mater, 2016, 26: 3703-3710

59 Yin J, Qi L, Wang H. Sodium titanate nanotubes as negative electrode materials for sodium-ion capacitors. ACS Appl Mater Interfaces, 2012, 4: 2762-2768

60 Dong S, Shen L, Li H, et al. Pseudocapacitive behaviours of $\mathrm{Na}_{2} \mathrm{Ti}_{3} \mathrm{O}_{7} @ \mathrm{CNT}$ coaxial nanocables for high-performance sodium-ion capacitors. J Mater Chem A, 2015, 3: 21277-21283

61 Dong S, Wu L, Wang J, et al. Self-supported electrodes of $\mathrm{Na}_{2} \mathrm{Ti}_{3} \mathrm{O}_{7}$ nanoribbon array/graphene foam and graphene foam for quasi-solid-state Na-ion capacitors. J Mater Chem A, 2017, 5: 5806-5812

62 Li H, Peng L, Zhu Y, et al. Achieving high-energy-high-power density in a flexible quasi-solid-state sodium ion capacitor. Nano Lett, 2016, 16: 5938-5943

63 Qiu X, Zhang X, Fan LZ. In situ synthesis of a highly active $\mathrm{Na}_{2} \mathrm{Ti}_{3} \mathrm{O}_{7}$ nanosheet on an activated carbon fiber as an anode for high-energy density supercapacitors. J Mater Chem A, 2018, 6: 16186-16195

64 Wang $\mathrm{C}$, Xi Y, Wang $\mathrm{M}$, et al. Carbon-modified $\mathrm{Na}_{2} \mathrm{Ti}_{3} \mathrm{O}_{7} \cdot 2 \mathrm{H}_{2} \mathrm{O}$ nanobelts as redox active materials for high-performance supercapacitor. Nano Energy, 2016, 28: 115-123

65 Yang D, Sun X, Lim K, et al. Pre-sodiated nickel cobaltite for high-performance sodium-ion capacitors. J Power Sources, 2017, 362: 358-365

66 Ding R, Qi L, Wang H. An investigation of spinel $\mathrm{NiCo}_{2} \mathrm{O}_{4}$ as anode for Na-ion capacitors. Electrochim Acta, 2013, 114: 726735

67 Wang YX, Chou SL, Wexler D, et al. High-performance sodiumion batteries and sodium-ion pseudocapacitors based on $\mathrm{MoS}_{2} /$ graphene composites. Chem Eur J, 2014, 20: 9607-9612

68 Chauhan H, Singh MK, Kumar P, et al. Development of $\mathrm{SnS}_{2} /$ RGO nanosheet composite for cost-effective aqueous hybrid supercapacitors. Nanotechnology, 2017, 28: 025401

69 Wang R, Wang S, Peng X, et al. Elucidating the intercalation pseudocapacitance mechanism of $\mathrm{MoS}_{2}$-carbon monolayer interoverlapped superstructure: toward high-performance sodiumion-based hybrid supercapacitor. ACS Appl Mater Interfaces, 2017, 9: 32745-32755

70 Zhao C, Yu C, Zhang M, et al. Enhanced sodium storage capability enabled by super wide-interlayer-spacing $\mathrm{MoS}_{2}$ integrated on carbon fibers. Nano Energy, 2017, 41: 66-74

71 Niu F, Yang J, Wang N, et al. $\mathrm{MoSe}_{2}$-covered N,P-doped carbon nanosheets as a long-life and high-rate anode material for sodium-ion batteries. Adv Funct Mater, 2017, 27: 1700522

72 Zhao X, Cai W, Yang Y, et al. $\mathrm{MoSe}_{2}$ nanosheets perpendicularly grown on graphene with Mo-C bonding for sodium-ion capacitors. Nano Energy, 2018, 47: 224-234

73 Xia Z, Sun H, He X, et al. In situ construction of $\mathrm{CoSe}_{2} @$ verticaloriented graphene arrays as self-supporting electrodes for sodium-ion capacitors and electrocatalytic oxygen evolution. Nano Energy, 2019, 60: 385-393

74 Su Y, Zhitomirsky I. Asymmetric electrochemical supercapacitor, based on polypyrrole coated carbon nanotube electrodes. Appl Energy, 2015, 153: 48-55

$75 \mathrm{Su} \mathrm{Y}$, Zhitomirsky I. Hybrid $\mathrm{MnO}_{2}$ /carbon nanotube-VN/carbon nanotube supercapacitors. J Power Sources, 2014, 267: 235-242

76 Dong J, Jiang Y, Li Q, et al. Pseudocapacitive titanium oxynitride mesoporous nanowires with iso-oriented nanocrystals for ultrahigh-rate sodium ion hybrid capacitors. J Mater Chem A, 2017, 5: 10827-10835

77 Zhu C, Yang P, Chao D, et al. All metal nitrides solid-state asymmetric supercapacitors. Adv Mater, 2015, 27: 4566-4571

78 Dong S, Chen X, Gu L, et al. Facile preparation of mesoporous titanium nitride microspheres for electrochemical energy storage. ACS Appl Mater Interfaces, 2011, 3: 93-98

79 Wang Q, Wen Z, Li J. A hybrid supercapacitor fabricated with a carbon nanotube cathode and $\mathrm{a} \mathrm{TiO}_{2}-\mathrm{B}$ nanowire anode. $\mathrm{Adv}$ Funct Mater, 2006, 16: 2141-2146

80 Xie X, Zhao MQ, Anasori B, et al. Porous heterostructured MXene/carbon nanotube composite paper with high volumetric capacity for sodium-based energy storage devices. Nano Energy, 2016, 26: 513-523

81 Wang X, Kajiyama S, Iinuma $\mathrm{H}$, et al. Pseudocapacitance of MXene nanosheets for high-power sodium-ion hybrid capacitors. Nat Commun, 2015, 6: 6544

82 Kurra N, Alhabeb M, Maleski K, et al. Bistacked titanium carbide 
(MXene) anodes for hybrid sodium-ion capacitors. ACS Energy Lett, 2018, 3: 2094-2100

83 Chen S, Wu C, Shen L, et al. Challenges and perspectives for NASICON-type electrode materials for advanced sodium-ion batteries. Adv Mater, 2017, 29: 1700431

84 Zhang S, Liu Y, Han Q, et al. Development and characterization of aqueous sodium-ion hybrid supercapacitor based on $\mathrm{NaTi}_{2}$ $\left(\mathrm{PO}_{4}\right)_{3} / /$ activated carbon. J Alloys Compd, 2017, 729: 850-857

85 Phan TN, Gong MK, Thangavel R, et al. Ordered mesoporous carbon CMK-8 cathodes for high-power and long-cycle life sodium hybrid capacitors. J Alloys Compd, 2018, 743: 639-645

86 Jian Z, Raju V, Li Z, et al. A high-power symmetric Na-ion pseudocapacitor. Adv Funct Mater, 2015, 25: 5778-5785

87 Whitacre JF, Shanbhag S, Mohamed A, et al. A polyionic, largeformat energy storage device using an aqueous electrolyte and thick-format composite $\mathrm{NaTi}_{2}\left(\mathrm{PO}_{4}\right)_{3}$ /activated carbon negative electrodes. Energy Tech, 2015, 3: 20-31

88 Wei T, Yang G, Wang C. Iso-oriented $\mathrm{NaTi}_{2}\left(\mathrm{PO}_{4}\right)_{3}$ mesocrystals as anode material for high-energy and long-durability sodiumion capacitor. ACS Appl Mater Interfaces, 2017, 9: 31861-31870

89 Thangavel R, Kaliyappan K, Kang K, et al. Going beyond lithium hybrid capacitors: Proposing a new high-performing sodium hybrid capacitor system for next-generation hybrid vehicles made with bio-inspired activated carbon. Adv Energy Mater, 2016, 6: 1502199

90 Thangavel R, Moorthy B, Kim DK, et al. Pushing the energy output and cyclability of sodium hybrid capacitors at high power to new limits. Adv Energy Mater, 2017, 7: 1602654

91 Wang R, Lang J, Zhang P, et al. Fast and large lithium storage in $3 \mathrm{D}$ porous $\mathrm{VN}$ nanowires-graphene composite as a superior anode toward high-performance hybrid supercapacitors. Adv Funct Mater, 2015, 25: 2270-2278

92 Karthikeyan K, Amaresh S, Kim KJ, et al. A high performance hybrid capacitor with $\mathrm{Li}_{2} \mathrm{CoPO}_{4} \mathrm{~F}$ cathode and activated carbon anode. Nanoscale, 2013, 5: 5958-5964

93 Kaliyappan K, Amaresh S, Lee YS. $\mathrm{LiMnBO}_{3}$ nanobeads as an innovative anode material for high power lithium ion capacitor applications. ACS Appl Mater Interfaces, 2014, 6: 11357-11367

94 Du H, Yang H, Huang C, et al. Graphdiyne applied for lithiumion capacitors displaying high power and energy densities. Nano Energy, 2016, 22: 615-622

95 Lim E, Jo C, Kim H, et al. Facile synthesis of $\mathrm{Nb}_{2} \mathrm{O}_{5} @$ carbon core-shell nanocrystals with controlled crystalline structure for high-power anodes in hybrid supercapacitors. ACS Nano, 2015, 9: 7497-7505

96 Kim H, Park KY, Hong J, et al. All-graphene-battery: bridging the gap between supercapacitors and lithium ion batteries. Sci Rep, 2014, 4: 5278

97 Yuan Y, Wang C, Lei K, et al. Sodium-ion hybrid capacitor of high power and energy density. ACS Cent Sci, 2018, 4: 1261-1265

98 Kim MS, Lim E, Kim S, et al. General synthesis of N-doped macroporous graphene-encapsulated mesoporous metal oxides and their application as new anode materials for sodium-ion hybrid supercapacitors. Adv Funct Mater, 2017, 27: 1603921

99 Wasiński K, Półrolniczak P, Walkowiak M. Proof-of-concept study of a new type sodium-ion hybrid electrochemical capacitor with organic electrolyte. Electrochim Acta, 2018, 259: 850-854

100 Fleischmann S, Widmaier M, Schreiber A, et al. High voltage asymmetric hybrid supercapacitors using lithium- and sodiumcontaining ionic liquids. Energy Storage Mater, 2019, 16: 391-399
101 Wang F, Wang X, Chang Z, et al. A quasi-solid-state sodium-ion capacitor with high energy density. Adv Mater, 2015, 27: 69626968

102 Ding J, Wang H, Li Z, et al. Peanut shell hybrid sodium ion capacitor with extreme energy-power rivals lithium ion capacitors. Energy Environ Sci, 2015, 8: 941-955

103 Song MY, Kim NR, Cho SY, et al. Asymmetric energy storage devices based on surface-driven sodium-ion storage. ACS Sustain Chem Eng, 2017, 5: 616-624

104 Wang P, Yang B, Zhang G, et al. Three-dimensional carbon framework as a promising anode material for high performance sodium ion storage devices. Chem Eng J, 2018, 353: 453-459

105 Ajuria J, Redondo E, Arnaiz M, et al. Lithium and sodium ion capacitors with high energy and power densities based on carbons from recycled olive pits. J Power Sources, 2017, 359: 17-26

106 Babu B, Shaijumon MM. High performance sodium-ion hybrid capacitor based on $\mathrm{Na}_{2} \mathrm{Ti}_{2} \mathrm{O}_{4}(\mathrm{OH})_{2}$ nanostructures. J Power Sources, 2017, 353: 85-94

107 Cho SY, Yoon HJ, Kim NR, et al. Sodium-ion supercapacitors based on nanoporous pyroproteins containing redox-active heteroatoms. J Power Sources, 2016, 329: 536-545

108 Ding J, Li Z, Cui K, et al. Heteroatom enhanced sodium ion capacity and rate capability in a hydrogel derived carbon give record performance in a hybrid ion capacitor. Nano Energy, 2016, 23: $129-137$

109 Phattharasupakun N, Wutthiprom J, Ma N, et al. Sodium-ion diffusion and charge transfer kinetics of sodium-ion hybrid capacitors using bio-derived hierarchical porous carbon. Electrochim Acta, 2018, 286: 55-64

110 Yu F, Liu Z, Zhou R, et al. Pseudocapacitance contribution in boron-doped graphite sheets for anion storage enables highperformance sodium-ion capacitors. Mater Horiz, 2018, 5: 529535

111 Wang C, Wang F, Liu Z, et al. N-doped carbon hollow microspheres for metal-free quasi-solid-state full sodium-ion capacitors. Nano Energy, 2017, 41: 674-680

112 Yang B, Chen J, Lei S, et al. Spontaneous growth of 3D framework carbon from sodium citrate for high energy- and power-density and long-life sodium-ion hybrid capacitors. Adv Energy Mater, 2018, 8: 1702409

113 You Y, Wu XL, Yin YX, et al. High-quality Prussian blue crystals as superior cathode materials for room-temperature sodium-ion batteries. Energy Environ Sci, 2014, 7: 1643-1647

114 Piernas-Muñoz MJ, Castillo-Martínez E, Gómez-Cámer JL, et al. Optimizing the electrolyte and binder composition for sodium Prussian blue, $\mathrm{Na}_{1-x} \mathrm{Fe}_{x+(1 / 3)}(\mathrm{CN})_{6} \cdot y \mathrm{H}_{2} \mathrm{O}$, as cathode in sodium ion batteries. Electrochim Acta, 2016, 200: 123-130

115 Liu Y, Qiao Y, Zhang W, et al. Sodium storage in Na-rich $\mathrm{Na}_{x} \mathrm{FeFe}(\mathrm{CN})_{6}$ nanocubes. Nano Energy, 2015, 12: 386-393

$116 \mathrm{Xu} \mathrm{Y}$, Zheng S, Tang H, et al. Prussian blue and its derivatives as electrode materials for electrochemical energy storage. Energy Storage Mater, 2017, 9: 11-30

117 Lu K, Song B, Gao X, et al. High-energy cobalt hexacyanoferrate and carbon micro-spheres aqueous sodium-ion capacitors. J Power Sources, 2016, 303: 347-353

118 Zhao F, Wang Y, Xu X, et al. Cobalt hexacyanoferrate nanoparticles as a high-rate and ultra-stable supercapacitor electrode material. ACS Appl Mater Interfaces, 2014, 6: 11007-11012

119 Wang JG, Zhang Z, Zhang X, et al. Cation exchange formation of Prussian blue analogue submicroboxes for high-performance Na- 
ion hybrid supercapacitors. Nano Energy, 2017, 39: 647-653

120 Senthilkumar B, Sankar KV, Vasylechko L, et al. Synthesis and electrochemical performances of maricite- $\mathrm{NaMPO}_{4}(\mathrm{M}=\mathrm{Ni}, \mathrm{Co}$, $\mathrm{Mn}$ ) electrodes for hybrid supercapacitors. RSC Adv, 2014, 4: 53192-53200

121 Sundaram MM, Watcharatharapong $\mathrm{T}$, Chakraborty $\mathrm{S}$, et al. Synthesis, and crystal and electronic structure of sodium metal phosphate for use as a hybrid capacitor in non-aqueous electrolyte. Dalton Trans, 2015, 44: 20108-20120

122 Béguin F, Presser V, Balducci A, et al. Carbons and electrolytes for advanced supercapacitors. Adv Mater, 2014, 26: 2219-2251

123 Usui H, Domi Y, Shimizu M, et al. Niobium-doped titanium oxide anode and ionic liquid electrolyte for a safe sodium-ion battery. J Power Sources, 2016, 329: 428-431

124 Zhang Y, Nie $\mathrm{P}, \mathrm{Xu} \mathrm{C}$, et al. High energy aqueous sodium-ion capacitor enabled by polyimide electrode and high-concentrated electrolyte. Electrochim Acta, 2018, 268: 512-519

125 Bae KL, Kim K. Flexible sodium-ion supercapacitor based on polypyrrole/carbon electrode by use of harmless aqueous electrolyte for wearable devices. Int J Energy Res, 2017, 41: 1335-1341

126 Xiong Q, Zheng $\mathrm{C}$, Chi $\mathrm{H}$, et al. Reconstruction of $\mathrm{TiO}_{2} / \mathrm{MnO}_{2}-\mathrm{C}$ nanotube/nanoflake core/shell arrays as high-performance supercapacitor electrodes. Nanotechnology, 2017, 28: 055405

127 Lee J, Kim S, Kim C, et al. Hybrid capacitive deionization to enhance the desalination performance of capacitive techniques. Energy Environ Sci, 2014, 7: 3683-3689

128 Forsyth $\mathrm{M}$, Yoon $\mathrm{H}$, Chen $\mathrm{F}$, et al. Novel $\mathrm{Na}^{+}$ion diffusion mechanism in mixed organic-inorganic ionic liquid electrolyte leading to high $\mathrm{Na}^{+}$transference number and stable, high rate electrochemical cycling of sodium cells. J Phys Chem C, 2016, 120: 4276-4286

129 Mendes TC, Zhou F, Barlow AJ, et al. An ionic liquid based sodium metal-hybrid supercapacitor-battery. Sustain Energy Fuels, 2018, 2: 763-771

$130 \mathrm{Xu} \mathrm{Z,} \mathrm{Xie} \mathrm{F,} \mathrm{Wang} \mathrm{J,} \mathrm{et} \mathrm{al.} \mathrm{All-cellulose-based} \mathrm{quasi-solid-state}$ sodium-ion hybrid capacitors enabled by structural hierarchy. Adv Funct Mater, 2019, 334: 1903895

131 Wang Z, Li H, Tang Z, et al. Hydrogel electrolytes for flexible aqueous energy storage devices. Adv Funct Mater, 2018, 28: 1804560

132 Wang D, Li H, Liu Z, et al. A nanofibrillated cellulose/polyacrylamide electrolyte-based flexible and sewable high-performance $\mathrm{Zn}-\mathrm{MnO}_{2}$ battery with superior shear resistance. Small, 2018, 14: 1803978

133 González-Gil A, Palacin R, Batty P. Sustainable urban rail systems: Strategies and technologies for optimal management of regenerative braking energy. Energy Convers Manage, 2013, 75: 374-388

Acknowledgements This work was financially supported by the National Natural Science Foundation of China (51672308, 51972025 and 61888102).

Author contributions The paper was written with contributions from all authors. All authors have given approval to the final version of the paper.

Conflict of interest The authors declare that they have no conflict of interest.

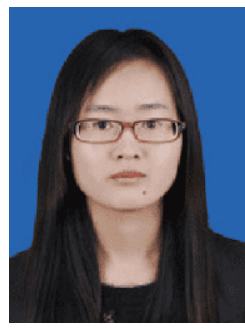

Rui Jia received her BE degree in 2015 from Huaqiao University and ME degree in 2018 from Qingdao University. She is a $\mathrm{PhD}$ candidate at the College of Mathematics and Physics, University of Science and Technology Beijing. Her research interests mainly focus on sodium-ion batteries and hybrid supercapacitors.

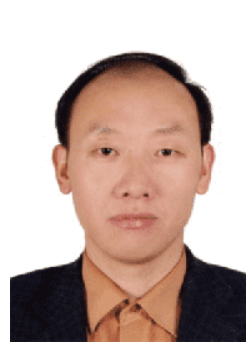

Guozhen Shen received his BSc degree (1999) in chemistry from Anhui Normal University and $\mathrm{PhD}$ degree (2003) in chemistry from the University of Science and technology of China. He joined the Institute of Semiconductors, Chinese Academy of Sciences as a Professor in 2013. His current research focuses on flexible electronics and printable electronics, including transistors, photodetectors, sensors and flexible energy storage and conversion devices.

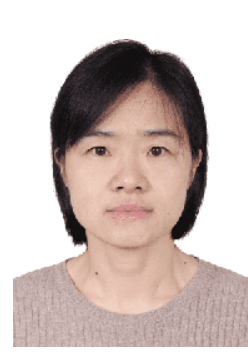

Di Chen received her BSc degree (1999) in chemistry from Anhui Normal University and $\mathrm{PhD}$ degree (2005) in chemistry from the University of Science and technology of China. She joined the University of Science and Technology Beijing as a Professor in 2014. Her current research focuses on energy storage materials and devices.

\section{钠离子混合电容器的研究进展和未来展望}

\author{
贾莕 ${ }^{1}$, 沈国震 ${ }^{2 *}$, 陈娣 ${ }^{*}$
}

摘要 现代社会对电力系统和能源存储设备的能量密度、功率密 度和工作寿命提出了更高的要求. 为了满足这一需求, 电池型负极 和电容型正极组成的新型钠离子混合电容由于具有储备资源丰富 和价格低廉的特点, 引起了人们的广泛关注. 值得一提的是, 钠离子 混合电容在电池和超级电容器这两种储能方式之间起到了关键的 桥梁作用, 使其在未来的大规模储能领域具有强大竞争力. 本文对 电池型负极材料和电容型正极材料进行了细致的分类和介绍, 并 对有机系电解质、水系电解质和离子液体电解质等多种电解质的 特点进行了深入讨论. 此外, 我们对钠离子混合电容的应用现状及 其在城市轨道交通中的潜在应用做了详细讨论. 最后, 分析了钠离 子混合电容目前所面临的挑战, 并对其未来的发展方向作出了展 望. 